\title{
A case study of wind farm effects using two wake parameterizations in the Weather Research and Forecasting (WRF) model (V3.7.1) in the presence of low-level jets
}

\author{
Xiaoli G. Larsén and Jana Fischereit \\ Wind Energy Department, Technical University of Denmark, Frederiksborgvej 399, Building 125, 4000 Roskilde, Denmark \\ Correspondence: Xiaoli G. Larsén (xgal@dtu.dk)
}

Received: 26 October 2020 - Discussion started: 22 December 2020

Revised: 5 May 2021 - Accepted: 10 May 2021 - Published: 2 June 2021

\begin{abstract}
While the wind farm parameterization by Fitch et al. (2012) in the Weather Research and Forecasting (WRF) model has been used and evaluated frequently, the explicit wake parameterization (EWP) by Volker et al. (2015) is less well explored. The openly available high-frequency flight measurements from Bärfuss et al. (2019a) provide an opportunity to directly compare the simulation results from the EWP and Fitch scheme with in situ measurements. In doing so, this study aims to complement the recent study by Siedersleben et al. (2020) by (1) comparing the EWP and Fitch schemes in terms of turbulent kinetic energy (TKE) and velocity deficit, together with FINO 1 measurements and synthetic aperture radar (SAR) data, and (2) exploring the interactions of the wind farm with low-level jets (LLJs). This is done using a bug-fixed WRF version that includes the correct TKE advection, following Archer et al. (2020).

Both the Fitch and the EWP schemes can capture the mean wind field in the presence of the wind farm consistently and well. TKE in the EWP scheme is significantly underestimated, suggesting that an explicit turbine-induced TKE source should be included in addition to the implicit source from shear. The value of the correction factor for turbineinduced TKE generation in the Fitch scheme has a significant impact on the simulation results. The position of the LLJ nose and the shear beneath the jet nose are modified by the presence of wind farms.
\end{abstract}

\section{Introduction}

Offshore wind energy has been developing fast in recent years. Consequently, wind farms are growing bigger and bigger in both capacity and spatial size. For instance, in the North Sea, a farm can extend over tens of kilometers and merge with neighboring farms, resulting in a cluster size of several thousand square kilometers, e.g., the Hornsea area $\left(7240 \mathrm{~km}^{2}\right)$; see 4Coffshore (2021) and Díaz and Guedes Soares (2020) for an overview of the current status of offshore wind farms. Wind turbines and farms extract momentum from the atmospheric flow and interact with it, causing reductions in wind speed and changes in turbulence in the wake regions. To assess such impacts over areas with sizes of modern farm clusters, mesoscale modeling has been shown to be a useful tool in including synoptical and mesoscale wind variability. Several mesoscale models have been used to study wind farm effects, and the Weather Research and Forecasting (WRF) model (Skamarock et al., 2007) is the most-used mesoscale model for studying this subject according to a recent review by Fischereit et al. (2021). There are mainly two kinds of methods to parameterize the effects of wind farms on the atmosphere: one is the implicit method that parameterizes the effects through an increase in surface roughness length, and the other is the explicit method that parameterizes the effects through an elevated momentum sink. In connection with the use of WRF, the wind farm parameterization (WFP) scheme (Fitch et al., 2012), called the Fitch scheme here, and the explicit wake parameterization (Volker et al., 2015), called the EWP scheme here, are the two most commonly applied explicit wind farm parame- 
terizations. Most previous studies have used the Fitch scheme (Fischereit et al., 2021).

The Fitch scheme has long been implemented in WRF, which makes it convenient for users regarding further development, investigation, application and validation. The EWP scheme, on the other hand, is not included in the official WRF repository, and it has not been explored and validated as frequently. Studies comparing the two schemes on the calculation of turbulent kinetic energy (TKE) are thus limited. Volker et al. (2015, 2017), Catton (2020), Pryor et al. (2020) and Shepherd et al. (2020) are among the few, with the first three addressing offshore wind farms and the last two onshore wind farms. These studies consistently show that the Fitch scheme generates significantly larger windfarm-induced TKE values than the EWP scheme does. The two schemes differ with respect to their treatment of turbineinduced forces in the momentum equation and their treatment of wind farms as a source of TKE. In the Fitch scheme, the turbine-induced force is represented by a local thrust force (as a function of the thrust coefficient) acting on the turbineswept area. In the EWP scheme, a grid-cell-averaged drag force is applied that accounts for a sub-grid-scale vertical wake expansion based on the concept from Tennekes and Lumley (1972). With respect to TKE, in the Fitch scheme wind turbines are treated as an explicit source of TKE. By neglecting mechanical losses, turbine-induced TKE is a function of the difference between the power and the thrust coefficients. In the EWP scheme, no explicit source term is considered for wind-farm-related TKE, and the turbine-induced TKE arises solely from the shear production in the wind farm wake.

TKE describes the fluctuation of kinetic energy and is related to turbulence, which is a key wind-energy application parameter. The modeling of wind-farm-induced TKE from the Fitch scheme has been previously evaluated in a number of case studies with measurements from profiling lidars (Lee and Lundquist, 2017a, b). With considerable uncertainties embedded with the lidar technique, Lee and Lundquist (2017a, b) showed that TKE from the Fitch scheme can capture the general pattern from the measurements. Siedersleben et al. (2020) (hereinafter S2020) used in situ highfrequency airborne measurements to evaluate TKE from the Fitch scheme in WRF for three case studies. They found that the Fitch scheme overestimates the TKE on the upwind side of the wind farm and underestimates it on the downwind side. They also noted that capturing the background meteorology is crucial to evaluate the performance of the scheme, which they managed only within their case study II.

During case study II of S2020, low-level jets were present over the area. Low-level jets (LLJs) over the southern North Sea are mostly associated with relatively warm continental air being advected over a cooler sea surface, where a stable internal boundary layer develops, causing quasi-frictional decoupling and an acceleration of air mass. The phenomena are rather common in coastal regions, and they have been studied in a long list of literature (e.g., Smedman et al., 1993, 1995; Dörenkämper et al., 2015; Wagner et al., 2019; Kalverla et al., 2019). Wagner et al. (2019) showed that LLJs are a common phenomenon in the southern North Sea area: by analyzing 1.5 years of campaign measurements using lidar and passive microwave radiometer measurements over the southern North Sea, they found that "LLJs occurred $14.5 \%$ of the time (449 of 3107 measurements) and on $64.8 \%$ (162 of 250) of the days". Flow from the southwest (such as in case II) is one of the favorable conditions in forming LLJs in this area. The Wagner et al. data show that LLJs in association with flow from the south and the southwest typically have a jet nose (wind speed maximum) height between 200 and $300 \mathrm{~m}$. This is expected to have a non-negligible impact on the turbine performance, which is not only related to the increased wind resources, but also to the unusual vertical distribution of wind shear, with enhanced shear beneath the jet nose and negative shear above it. Thus, turbulence is also affected, causing considerable additional uncertainties in the estimation of relevant key parameters such as turbulence intensity, gust and loads. It has not yet been documented in the literature how the structure of an LLJ is affected by the presence of large wind farms. There is also a lack of published studies showing wind farm wakes in the presence of LLJs.

The purpose of this study is thus twofold: first, it refers to what S2020 pointed out: "For comparison, it would be interesting to simulate case study II with the wind farm parameterization of Volker et al. (2015)". With the availability of the high-frequency velocity measurements published in Bärfuss et al. (2019a), this study contributes to this knowledge gap by revisiting case study II in S2020 and comparing the wind farm effects modeled through the EWP and the Fitch schemes. This study will thus also be the first to use measurements to verify the calculations of TKE in the EWP scheme. Second, we use case study II from 14 October 2017 in S2020 to examine the wind characteristics under the impact of both wind farm wakes and LLJs.

The methods used here are introduced in Sect. 2, including the measurements and the WRF model setup. The results will be presented in Sect. 3, followed by a discussion in Sect. 4 and conclusions in Sect. 5.

\section{Method}

The case study from 14 October 2017 is modeled using WRF v3.7.1 with both the EWP and Fitch wind farm parameterization schemes; details of the model setup are given in Sect. 2.2. The model output will be analyzed together with various measurements in line with S2020. These measurements are introduced in Sect. 2.1. In this study, time in both the measurements and the modeled data is presented in UTC. 
Table 1. Time of the profile flights (see tracks 1-6 in Fig. 2) and transect flights (see Fig. 2, transect a).

\begin{tabular}{lrr}
\hline Flight no. & Start & End \\
\hline profile 1 & $2017-10-1413: 22: 59.700$ & $2017-10-1413: 25: 08.410$ \\
profile 2 & $2017-10-1414: 14: 41.600$ & $2017-10-1414: 17: 10.470$ \\
profile 3 & $2017-10-1415: 13: 31.260$ & $2017-10-1415: 15: 53.240$ \\
profile 4 & $2017-10-1416: 10: 21.570$ & $2017-10-1416: 12: 49.110$ \\
profile 5 & $2017-10-1416: 16: 35.240$ & $2017-10-1416: 19: 55.230$ \\
profile 6 & $2017-10-1416: 23: 22.060$ & $2017-10-1416: 25: 05.150$ \\
\hline transect 1 & $2017-10-1414: 20: 50.860$ & $2017-10-1414: 30: 12.370$ \\
transect 2 & $2017-10-1414: 34: 41.180$ & $2017-10-1414: 44: 37.520$ \\
transect 3 & $2017-10-1414: 48: 27.970$ & $2017-10-1414: 57: 43.640$ \\
transect 4 & $2017-10-1415: 01: 38.120$ & $2017-10-1415: 11: 34.970$ \\
transect 5 & $2017-10-1415: 45: 01.130$ & $2017-10-1415: 54: 05.160$ \\
transect 6 & $2017-10-1415: 58: 29.630$ & $2017-10-1416: 08: 34.810$ \\
\hline
\end{tabular}

\subsection{Measurements}

Case study II from S2020 took place on 14 October 2017. Along with warm air advection from land to sea, LLJs formed. Wind farm wakes were generated, which is obvious from the synthetic aperture radar (SAR) data as the streaks of reduced wind speed, as shown in their Fig. 4a, which is reproduced here in Fig. 1a. Three types of measurements are used here to study this event, which will be described individually in the following.

The first are the publicly available airborne measurement data published in Bärfuss et al. (2019a), described in Lampert et al. (2020) and Platis et al. (2018), and analyzed in S2020. The measurements are briefly introduced here, and their details can be found in these publications. The flight track on 14 October 2017 is reproduced here in Fig. 2. The transect flight over the wind farm is indicated in green and labeled "a". The colored blocks labeled with digits 1 to 6 indicate profiling flights along the track from the surface to about $600 \mathrm{~m}$. The start and end times of each profiling flight are provided in Table 1 . The profile data provide background information and are not affected by wind farm wakes (see Fig. 2 for their position relative to the farms). We call these profile-flight data. In contrast, the transect flight above the wind farm at $250 \mathrm{~m}$ of height is affected by the farm. We call these transect-flight data.

We downloaded the flight data from Bärfuss et al. (2019a). The data include, among others, temperature $T(\mathrm{~K})$, pressure $P(\mathrm{hPa})$, and the along-wind, cross-wind and vertical wind components, $u, v$ and $w$, respectively. Following S2020, we calculated the potential temperature $\theta$ from temperature $T$ and pressure $P$ using $\theta=T \cdot\left(P_{0} / P\right)^{0.2859}$, where $P_{0}=1000 \mathrm{hPa}$. The flight measurements are sampled at a frequency of $100 \mathrm{~Hz}$ at an aircraft ground speed of $66 \mathrm{~m} \mathrm{~s}^{-1}$, corresponding to a horizontal resolution of $0.66 \mathrm{~m}$ (Platis et al., 2018). The flights over Godewind 1 were conducted at an elevation of $250 \mathrm{~m}$, slightly above the rotor top $(187 \mathrm{~m}$, with hub height $110 \mathrm{~m}$ and diameter $154 \mathrm{~m}-\mathrm{S} 2020$; see also Table 4). For the analyses of the vertical profile, we averaged the profile-flight data over a vertical interval of $10 \mathrm{~m}$. For the transect-flight data, TKE is calculated following TKE = $0.5 \cdot\left(\sigma_{u}^{2}+\sigma_{v}^{2}+\sigma_{w}^{2}\right)$, where $\sigma_{u}, \sigma_{v}$ and $\sigma_{w}$ are standard deviations of the three wind components. The standard deviations are derived over data lengths of both 2 and $1.5 \mathrm{~km}$. The choice of the data length is made following the argument in Platis et al. (2018) for the turbulence length scales. They used a data length of $1.5 \mathrm{~km}$. Given the background wind speed of approximately $10-15 \mathrm{~m} \mathrm{~s}^{-1}$, the timescales over both 2 and $1.5 \mathrm{~km}$ are on the order of a couple of minutes, which is a reasonable integral timescale for separating boundary-layer turbulence and external fluctuations. Our analyses were made using both 2 and $1.5 \mathrm{~km}$ but are presented only for $2 \mathrm{~km}$ in order to match the spatial horizontal resolution of the WRF model; details are given in Sect. 3.

Wind farms included in the WRF modeling are shown on a larger map in Fig. 3a, and the details of these farms are provided in Table 4. Figure $3 \mathrm{~b}$ is a close-up of Fig. 3a over the marked area, with the two closest consecutive rows of WRF model grids shown over the Godewind 1 farm (in black and red), covering flight track "a" (in green). An additional row of WRF grid points (in purple) is chosen east of the farm in the wake-affected area. These three rows are denoted as transect black, transect red and transect purple according to the colors in our analysis. They will be used for analyzing the transect distribution of wind speed and TKE.

The second dataset originates from the FINO 1 met mast. In Fig. 3b, the location of the FINO 1 mast is marked as $F 1$. Note that for our studied case, with a wind direction from about $240^{\circ}$ (Fig. 5), the flow passes the wind farm Borkum Riffgrund before reaching $F 1$, resulting in reduced wind speed downwind of the farm, including at FINO 1 (see Fig. 1a). The $10 \mathrm{~min}$ values of wind speed from 30 to $100 \mathrm{~m}$ and wind direction from 30 to $90 \mathrm{~m}$ on 14 October are from FINO 1 utilized in this study.

The third measurement type is the SAR data. The wind farm wakes can be seen as reduced wind speed in Fig. 1a, for which the wind field was retrieved from ENVISAT SAR at 17:17 UTC on 14 October 2017. The retrieval uses the empirical relationship between the $10 \mathrm{~m}$ wind speed and the radar backscatter that depends on the local wind-generated wind waves (Valenzuela, 1978; Hersbach et al., 2007). The spatial resolution of the SAR data shown in Fig. 1a is about $500 \mathrm{~m}$. Figure 1a is made from more than one SAR scene; even though the farm wake pattern is continuous across scenes, there seems to be an artificial change in wind speed east of about $6.5^{\circ} \mathrm{E}$, which was also present in S2020. Due to these uncertainties, the SAR data will only be analyzed qualitatively. 


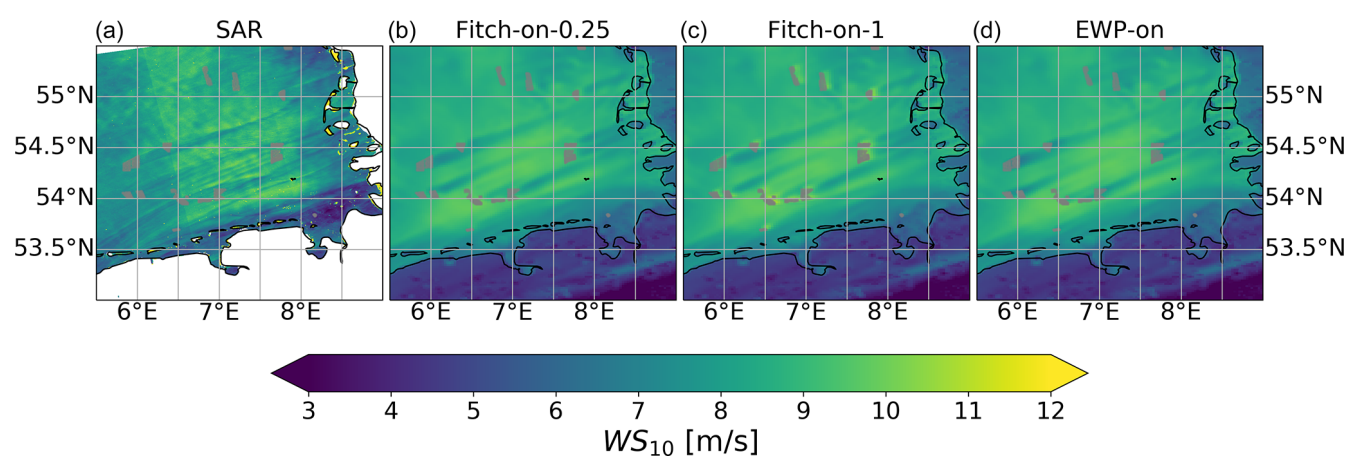

Figure 1. Wind speed $\left(\mathrm{m} \mathrm{s}^{-1}\right)$ at about $10 \mathrm{~m}$ of height (a) from SAR at 17:17 UTC on 14 October 2017 and (b-d) from WRF at 17:10 on 14 October for different scenarios as in Table 3. The satellite data in (a) are taken from https://satwinds.windenergy.dtu.dk/ (last access: 29 May 2021).

Table 2. WRF parameterization, boundary conditions and forcing data employed for the performed simulations.

\begin{tabular}{lll}
\hline Category & Subcategory & Details (option number) \\
\hline Schemes & PBL & MYNN (Nakanishi and Niino, 2009) \\
& Surface layer & Monin-Obukhov similarity \\
& Microphysics & New Thompson et al. scheme (Thompson et al., 2004) \\
& Radiation & RRTMG scheme (Iacono et al., 2008) \\
& Cumulus parameterization & Kain-Fritsch scheme on domain 1 (Kain and Fritsch, 1993) \\
\hline Boundary and forcing data & Dynamical forcing & ERA5 on pressure levels every 6h \\
& Land use data & CORINE from 2017 \\
& Sea surface temperature & OSTIA (Donlon et al., 2012) \\
& Land surface model & NOAH-LSM \\
\hline
\end{tabular}

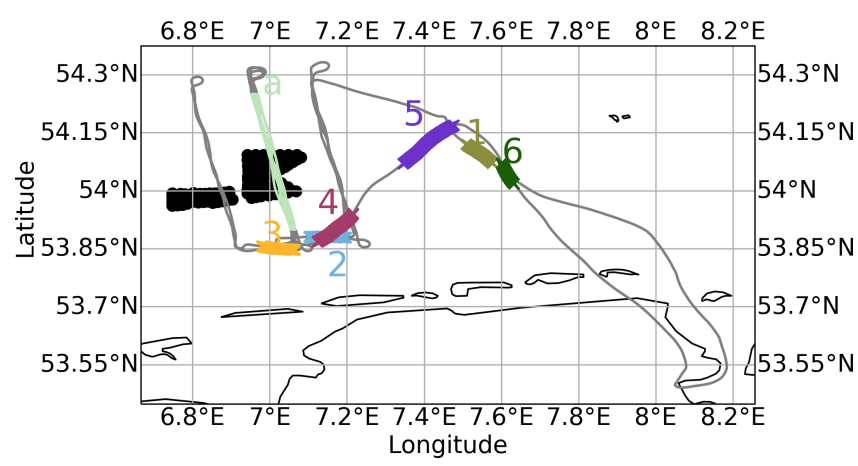

Figure 2. Flight tracks on 14 October 2017. The track labeled "a" provides transect-flight data over the wind farm at about $250 \mathrm{~m}$. Tracks labeled with numbers 1 to 6 provide the profile-flight data (see also Table 1). The flight track has been extracted from Bärfuss et al. (2019b).

\subsection{Modeling}

Important elements for accurately simulating LLJs using WRF include model domain configuration, initialization and boundary forcing data, horizontal and vertical spatial resolutions, and planetary boundary layer (PBL) schemes, as explored in, e.g., Nunalee and Basu (2014), Wagner et al.
Table 3. Overview of performed simulations.

\begin{tabular}{lll}
\hline Denotation & $\begin{array}{l}\text { Wind farm } \\
\text { parameterization }\end{array}$ & $\begin{array}{l}\text { TKE } \\
\text { advection }\end{array}$ \\
\hline EWP & EWP & on \\
EWP-off & EWP & off \\
Fitch-on-0.25 & Fitch & on; $\alpha=0.25$ \\
Fitch-on-1 & Fitch & on; $\alpha=1$ \\
Fitch-off & Fitch & off \\
Fitch-on-old & Fitch & on (before bug fix) \\
NWF & No & on \\
NWF-off & No & off \\
\hline
\end{tabular}

(2019), Kalverla et al. (2019), Siedersleben et al. (2020) and Tay et al. (2020). These studies suggested different best choices for the WRF setup in order to capture the LLJ characteristics. In our setup, we followed the general recommendations in the literature. These studies recommend a horizontal spatial resolution of $2 \mathrm{~km}$ in the innermost model domain and a large number of vertical model levels, e.g., 80 with 21 in the lowest $200 \mathrm{~m}$. They also suggest that ERA5 data (ERA5, 2021) are good as the initial and boundary forcing. Some studies show that the MYNN (Mellor-Yamada-NakanishiNiino) PBL scheme outperforms other schemes (Tay et al., 
Table 4. Details for all simulated wind farms. Note that for some wind farms the turbine models do not correspond to the actually installed one, since thrust and power curves were not available for all turbines: here turbines marked with ${ }^{1}$ are scaled from the NREL 5 MW turbine, and turbines marked with ${ }^{2}$ are scaled from the DTU $10 \mathrm{MW}$ turbine.

\begin{tabular}{|c|c|c|c|c|c|}
\hline Wind farm & Turbines & Turbine model & $\begin{array}{r}\text { Hub height } \\
{[\mathrm{m}]}\end{array}$ & $\begin{array}{r}\text { Rotor top } \\
{[\mathrm{m}]}\end{array}$ & $\begin{array}{l}\text { Wind farm area } \\
\qquad\left[\mathrm{km}^{2}\right]\end{array}$ \\
\hline Alpha Ventus & 12 & M5000-116 ${ }^{1}$,Senvion_5 $\mathrm{M}^{1}$ & $90.0,92.0$ & $148.0,155.0$ & 4 \\
\hline Amrumbank West & 80 & SWT-3.6-120 & 88 & 148 & 30 \\
\hline BARD Offshore & 80 & M5000-116 & 90 & 148 & 59 \\
\hline Borkum Riffgrund 1 & 78 & SWT-4.0-120 & 89.5 & 149.5 & 36 \\
\hline Butendiek & 80 & SWT-3.6-120 & 88 & 148 & 31 \\
\hline Gemini & 150 & SWT-4.0-130 & 95 & 160 & 68 \\
\hline Global Tech I & 80 & M5000-116 & 90 & 148 & 40 \\
\hline Gode Wind 1 & 55 & SWT-6.0-154_110 & 110 & 187 & 40 \\
\hline Gode Wind 2 & 42 & SWT-6.0-154_110 & 110 & 187 & 29 \\
\hline Horns Rev I & 80 & V80-2.0 & 67 & 107 & 21 \\
\hline Horns Rev II & 91 & SWT-2.3-93 & 68.3 & 114.8 & 33 \\
\hline Meerwind Süd and Ost & 80 & SWT-3.6-120 & 88 & 148 & 40 \\
\hline Nordsee One & 54 & $6.2 \mathrm{M} 126 \_90^{2}$ & 90 & 153 & 30 \\
\hline OWP Nordergründe & 18 & $6.2 \mathrm{M} 126 \_84^{2}$ & 84 & 147 & 3 \\
\hline OWP Nordsee Ost & 48 & $6.2 \mathrm{M} 126 \_95^{2}$ & 95 & 158 & 36 \\
\hline OWP Veja Mate & 67 & SWT-6.0-154 & 106 & 183 & 51 \\
\hline Offshore Windfarm DanTysk & 80 & SWT-3.6-120 & 88 & 148 & 65 \\
\hline Offshore Windfarm Sandbank & 72 & SWT-4.0-130 & 95 & 160 & 47 \\
\hline Offshore Windpark Riffgat & 30 & SWT-3.6-120 & 88 & 148 & 6 \\
\hline Trianel Windpark Borkum & 40 & M5000-116 & 90 & 148 & 23 \\
\hline
\end{tabular}

(a)

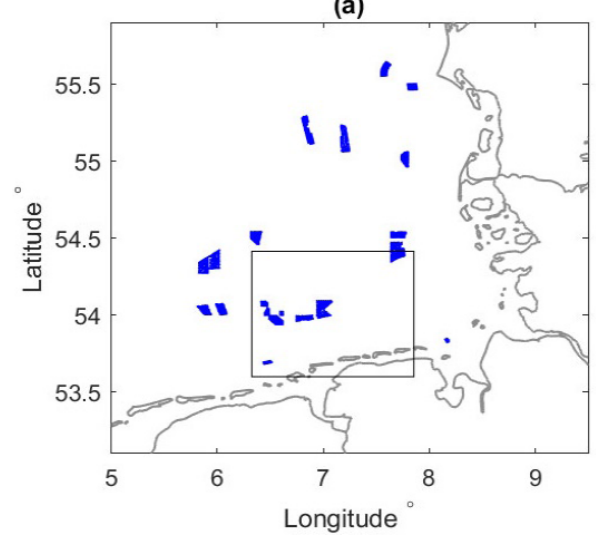

(b)

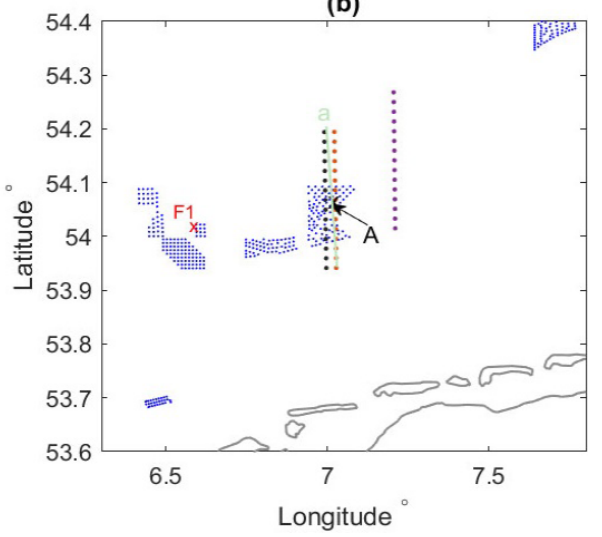

Figure 3. (a) Wind farm clusters that are included in the WRF modeling. The box includes the wind farms shown in (b), which is a close-up of (a); the two consecutive rows over the Godewind 1 farm are WRF grid points (black and red), and the flight legs are between the two rows of WRF grid points (transect labeled "a" in green as in Fig. 2) and one more row downwind (purple). Also marked are the location of the FINO 1 mast (F1) and point A on transect "a".

2020), and some other studies suggest that the MYNN PBL performs fine but not as good as the QNSE (quasi-normal scale elimination) scheme (Tay et al., 2020; Nunalee and Basu, 2014). However, since the Fitch scheme can only be used in connection with MYNN to calculate TKE developments, we were forced to use the MYNN PBL scheme.

We use WRF version 3.7.1 to simulate this case. The model contains three nested domains (Fig. 4), and the spa- tial resolutions are 18,6 and $2 \mathrm{~km}$ for domains I, II and III, respectively. Following the suggestion by S2020 and in agreement with other sensitivity studies (Tomaszewski and Lundquist, 2020; Lee and Lundquist, 2017a), we use 80 vertical layers with 21 layers below $200 \mathrm{~m}$ with a thickness of about $10 \mathrm{~m}$. Table 2 lists the parameterization schemes regarding PBL scheme, microphysics, radiation, land use, sea surface temperature (SST) and forcing data. 

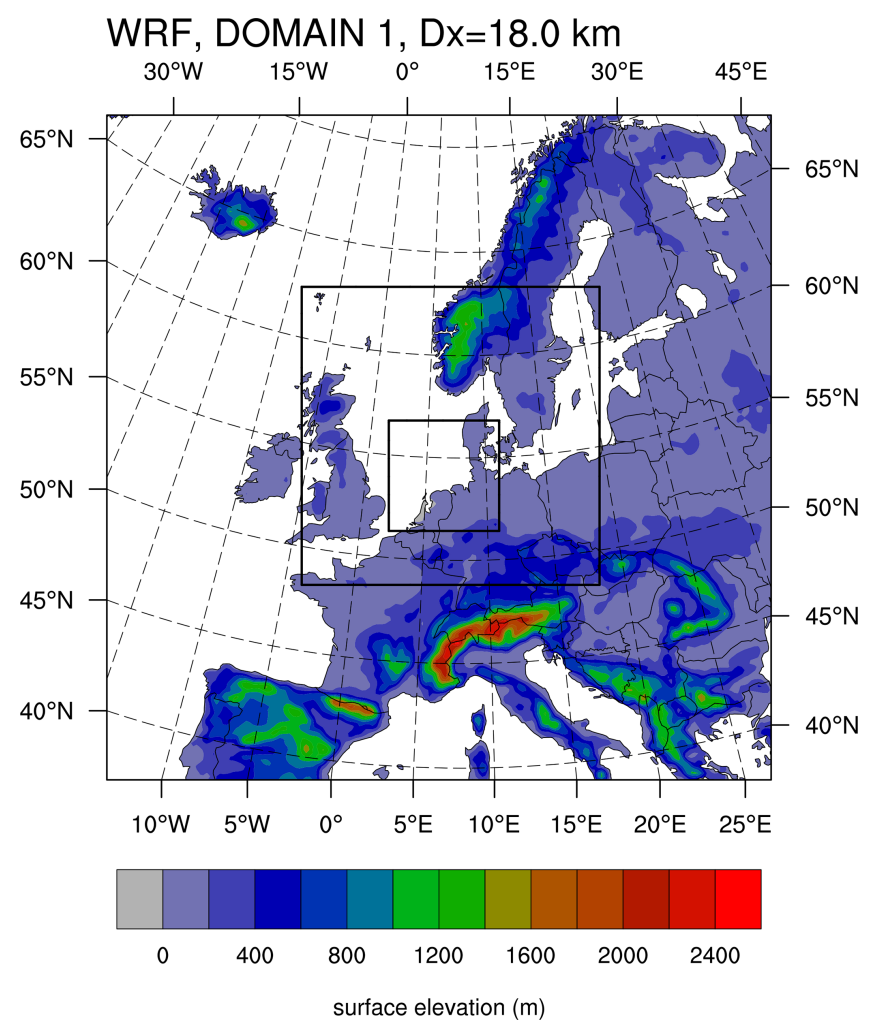

Figure 4. The three nested model domains in the WRF modeling; colors show topography.

The development of LLJs has been shown to be sensitive to the domain configuration. In our experiments, LLJs failed to develop when the southern land area included in the domain was too small, likely caused by an unsuccessful development of the stable internal boundary layer associated with warm air advection. This problem is solved by including more area in the model domain.

The WRF simulation starts at 06:00 on 14 October 2017 and runs to the end of the day. The simulation captures the development of LLJs and is sufficiently long to be compared to the available measurements. The model outputs are $10 \mathrm{~min}$ instantaneous values from each time step, including the longitudinal wind component $U$, the meridional wind component $V$, potential temperature $\theta$ and QKE, from which we further calculated the wind speed, the wind direction and TKE $(0.5 \cdot$ QKE).

The simulation has been run in three modes, one with the Fitch scheme, one with the EWP scheme and one without wind farms. Table 3 shows the complete list of all simulations and how each simulation is referenced in the text.

In WRF, advection of TKE can either be turned on or off. Several studies (Tomaszewski and Lundquist, 2020; Siedersleben et al., 2020), including S2020, explored the impact of deactivated and activated TKE advection in connection with the Fitch parameterization. However, a bug in WRF versions 3.5 to 4.2.1 led to an incorrect integration of the TKE gen- erated by wind farms into the overall TKE field, as reported in Archer et al. (2020). In addition to providing a fix for this bug, they also introduced a correction factor $\alpha$ so that the wind-farm-induced TKE in the Fitch scheme is now calculated as $C_{\mathrm{TKE}}=\alpha\left(C_{T}-C_{P}\right)$. Thus, $\alpha$ is used to adjust the magnitude of turbine-induced TKE. Based on their comparisons of a single turbine with large eddy simulations (LESs), Archer et al. (2020) recommended that $\alpha$ be set to a value smaller than 1 , with 0.25 being the default value.

We integrated the bug fix in WRF v3.7.1 as described in the Zenodo repository related to our study (Larsén and Fischereit, 2021). Using this version, we conduct three experiments using the Fitch scheme: advection turned off (denoted as Fitch-off; see Table 3), and advection turned on with $\alpha=1$ (Fitch-on-1) and turned on with $\alpha=0.25$ (Fitch-on-0.25). For the experiments with EWP and no wind farm, TKE advection is turned on by default, denoted as EWP and NWF, respectively. Most analysis will be based on the abovementioned five simulations. However, in the discussion (Sect. 4) we also comment on calculations from WRF before the bug fix (Fitch-on-old) in order to have a rough understanding of relevant results from the literature. For the sake of completeness, the simulations with the EWP scheme and no wind farms are also done with advection turned off, and they are denoted as EWP-off and NWF-off, respectively. The results of EWP-off and NWF-off will only be discussed briefly for comparison.

To include the effects of wind farms in the simulations, information on turbine location, hub height, rotor diameter, power coefficient and thrust coefficient is required. In our simulation, the locations of the turbines from the wind farms shown in Fig. 3 are obtained from three different sources: (1) Bundesnetzagentur (2019) for most German wind farms and (2) Energistyrelsen (2020) for Danish wind farms; (3) for other wind farms not included in these two datasets, turbine locations have been derived from SAR images in Langor (2019) and manually corrected to fit the wind farm shapes and turbine numbers from EMODnet (Emodnet, 2020). For the simulations in this study, only wind farms built before 2018 are included in accordance with the measurement time (Table 4). In S2020, three types of turbine are used, with Siemens SWT 6.0-154 for Godewind 1 and 2, Siemens SWT 3.6-120 for Meerwind Süd and Ost, and Senvion 6.2 for OWP Nordsee Ost (see Table 3 in S2020). They used the thrust and power coefficients of Siemens SWT 3.6-120 onshore for all turbines implemented in the simulation. In our study, we used a different turbine type for each wind farm according to the sources introduced above as far as they are available to us. For Alpha Ventus and BARD Offshore, we could not obtain the thrust and power coefficients for the actual turbine; therefore, we used the power and thrust curves of M5000-116 that are scaled from the NREL 5 MW turbine. The Senvion 6.2M126 turbine in the Nordsee One, OWP Nordergründe and OWP Nordsee Ost were similarly scaled from the DTU $10 \mathrm{MW}$ reference turbine. Other power and 
thrust curves have been taken from Langor (2019) or from WAsP (http://www.wasp.dk/, last access: 29 May 2021). In Table 4 the wind farms are listed with the turbine model used in the simulations. We used an initial length scale of 1.6 for the EWP scheme related to the sub-grid-scale vertical wake expansion. We also conducted simulations using the length scales 1.5 and 1.7 and found that the difference is negligible. In the literature, the length scale values 1.5 and 1.7 have been used (Badger et al., 2020; Volker et al., 2017, 2015), and Volker et al. (2015) show that the difference of using the values between 1.5 and 1.9 is negligible.

\section{Results and analysis}

\subsection{Low-level jets}

With warmer air moving from land over the sea in the direction of about $240^{\circ}$, a stable boundary layer (SBL) developed over the sea, as can be seen from the profile-flight data shown in Fig. 5a and c. The modeled potential temperature $\theta$ profiles consistently suggest the presence of the SBL, though the increasing of $\theta$ with height within the lowest $300 \mathrm{~m}$ is slightly smaller than the measurements. The direction veering is well captured in the lowest $300 \mathrm{~m}$. Above $300 \mathrm{~m}$, the measurements suggest a persistent wind direction of about $250^{\circ}$, while the modeled wind vector continues turning an additional $10-20^{\circ}$. LLJs are observed during these profiling flights, as shown in the distribution of wind speed with height in Fig. $5 g$; note that the time and location of these flights are different (Table 1 and Fig. 2). Figure $5 \mathrm{~g}$ clearly suggests that the wind structure of the LLJs is highly variant over time and space. This is also true for the corresponding modeled LLJs; see Fig. 5 g. Several of the measured wind speed profiles have more than one jet nose, with the lowest ones beneath $200 \mathrm{~m}$ and the highest ones at 350-400 m. This suggests a variation of the internal boundary layer in time and space in association with the flow from land. The model captures the jets at the level 200-400 m. At the same time, both measured and modeled TKEs generally decrease with height, with the modeled values being larger; see Fig. 5e and f. While the mean TKE values from the measurements are relatively small, their fluctuations are 2 times larger. These are not shown here in order to avoid too much noise in the plot. As none of these profile-flight data are affected by wind farm wakes, the modeled data are the same for NWF as well as the Fitch and EWP schemes. Therefore, in Fig. 5, only results from EWP are shown.

With the wind from the southwest direction, at the FINO 1 site, the LLJ structure is affected by the wake effect originating from the Borkum Riffgrund wind farm. Figure 6 shows the wind speed profiles at FINO 1 during three $1 \mathrm{~h}$ periods, with two during the flight periods (Fig. 6a and b) and one later in the afternoon (Fig. 6c). In each panel we show, in addition to the measurements (OBS), five simulations from
NWF, EWP, Fitch-on-1, Fitch-on-0.25 and Fitch-off. Each profile is a 10 min value for both measurements and model data. The measurements only reach up to $100 \mathrm{~m}$, which is way beneath the jet noses. From Fig. 6, it can be observed that the Fitch scheme in general results in a smaller wind reduction below hub height than the EWP scheme but a larger wind speed reduction above hub height. Thus, the average values from the surface to the rotor top height are comparable between the two schemes in this situation. For these wind profiles, Fitch-on-1 and Fitch-off are rather similar, whereas Fitch-on-0.25 shows a distinct kink at rotor top height, corresponding to a considerably larger wind reduction during 14:00 to 16:00. The kink is present in all three Fitch simulations, but it is absent in EWP. From Fig. 6, it is also clear that the wind speed reduction is not limited to the rotor area but extends up to the jet nose. Overall, the EWP scheme provides larger shear and better values at measurement heights for Fig. 6a and $b$ when the jet nose is high, but the Fitch scheme describes the profiles better at the measurement heights for Fig. $6 \mathrm{c}$ when the jet nose is low. It is also worth noting that the position of the LLJ nose is higher in the presence of the farm wake effect according to the WRF modeling.

These characteristics are also examined for point $\mathrm{A}$ as shown in Fig. 3. Point A is inside the Godewind 1 wind farm area and part of the flight leg denoted transect "a". Data at 15:00 are used, which are between the data used for Fig. 6a$\mathrm{b}$ and close to flight number 4 (Table 1). Here, both the wind speed profiles and the TKE profiles are compared between the five simulations in Fig. 7a and b, respectively. The above descriptions of the wind speed for FINO 1 are also true for point A, as can be seen in Fig. 7a. In the absence of wind farms (NWF), TKE decreases with height, as in Fig. 5. In the presence of farm wakes, for both EWP and Fitch, TKE values increase with height up to the rotor top and then decrease again to a value matching the free stream value. With the TKE advection turned on, TKE at point $\mathrm{A}$ is smaller than without advection. TKE in Fitch-on-1 is only slightly smaller than TKE in Fitch-off, whereas TKE in Fitch-on-0.25 is considerably smaller due to the smaller TKE source. This figure also shows that, over the rotor area, the variation of TKE with height from the EWP scheme is smoother and the magnitude of TKE significantly smaller in comparison with the Fitch scheme (Fig. 7b).

\subsection{Wind farm wake effects}

The vertical profile of wind speed at the FINO 1 site (Fig. 6) clearly shows the wake effect from the upstream Borkum Riffgrund wind farm. Figure 8 compares the measured and modeled time series of wind speed and wind direction at FINO 1. Here the modeled values at FINO 1 are weighted between the two closest grid points (one inside and one outside the farm) according to the distances between the grid points and the mast location. This is done because the closest grid point to FINO 1 is inside the farm, while in reality, FINO 1 
(a)

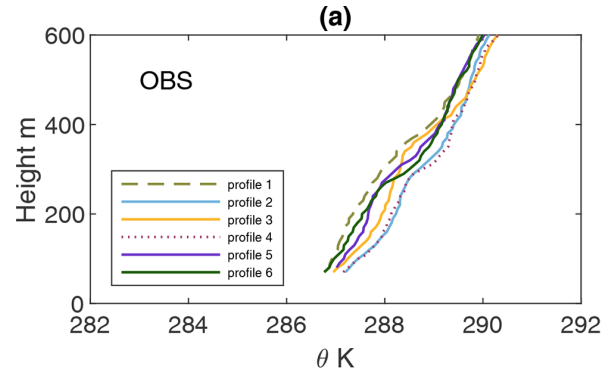

(c)

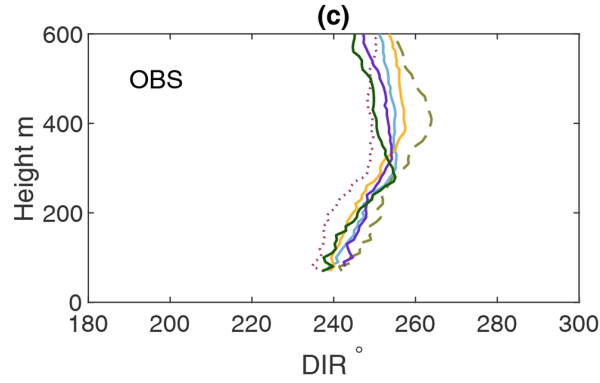

(e)

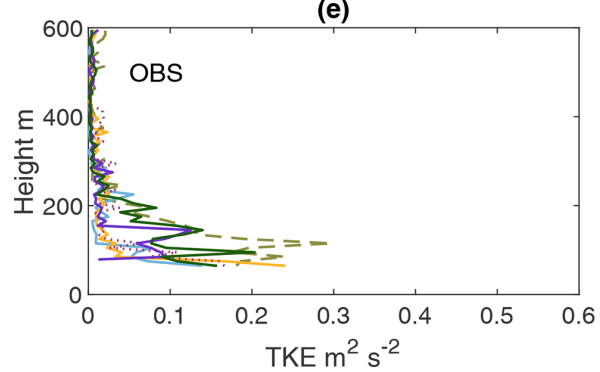

(g)

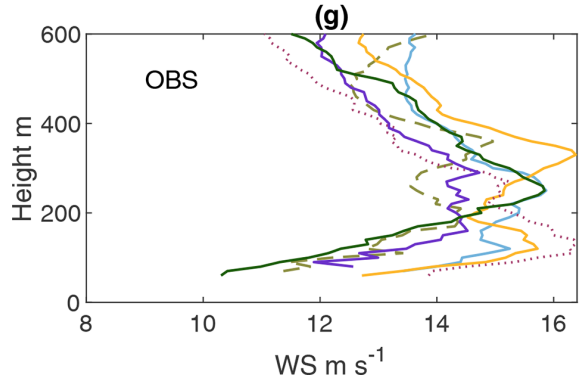

(b)

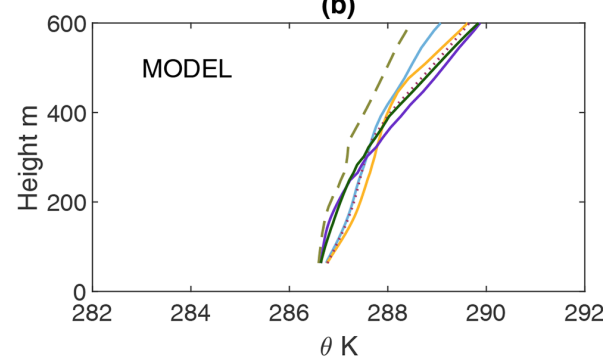

(d)

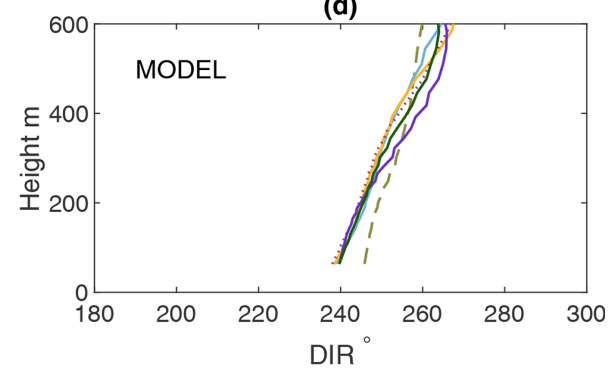

(f)

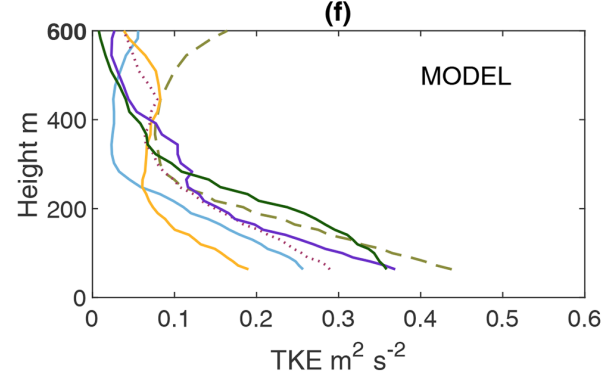

(h)

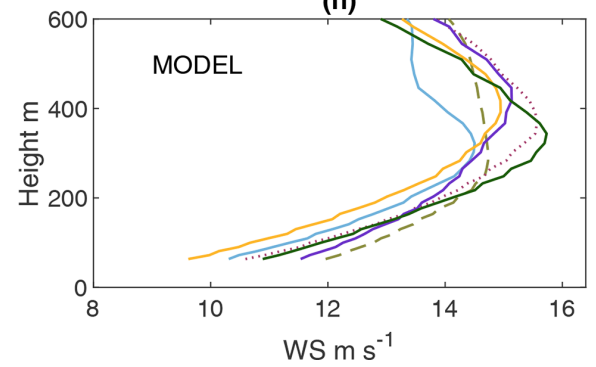

Figure 5. Vertical profiles of potential temperature (a, b), wind direction (c, d), TKE (e, f) and wind speed (g, h), both observed (OBS) and modeled (MODEL), at the center positions of profile flights 1 to 6 . Note that the modeled data are from the EWP scheme.

is on the edge and outside the farm. The three model modes (NWF, Fitch, EWP) provide the same wind direction calculations at $90 \mathrm{~m}$, which follow the measurements well until late in the afternoon when the modeled winds are more westerly than in reality (Fig. 8b). The wake impact on the wind speed at $100 \mathrm{~m}$ is clear, as shown in Fig. 8a. Between 12:00 and 24:00 on 14 October, the difference between the measured and modeled mean wind speed, $\langle\Delta U\rangle$, the standard deviation (SD) of the difference, and the absolute difference $\langle|\Delta U|\rangle$ are shown in Table 5 for the five simulations. Subtracting $\langle\Delta U\rangle$ of EWP from that of NWF suggests that, during this period, the wake effect is on average about $1.2 \mathrm{~m} \mathrm{~s}^{-1}$ when calculated using the EWP scheme. Similarly, it is $1.7 \mathrm{~m} \mathrm{~s}^{-1}$ when calculated using Fitch-on-1. Fitch-on-0.25 gives a significantly larger wind reduction, which is about $2 \mathrm{~m} \mathrm{~s}^{-1}$. Without taking the wind farm wakes into account, WRF overestimates the wind speed at $100 \mathrm{~m}$ by $1.41 \mathrm{~m} \mathrm{~s}^{-1}$. Overall, the Fitch scheme slightly overestimates and the EWP scheme slightly underestimates $\langle\Delta U\rangle$.

The wind farm wakes are visible from the SAR image at 17:17 UTC in Fig. 1a. The corresponding $10 \mathrm{~m}$ wind speeds from WRF using Fitch-on-0.25, Fitch-on-1 and EWP are shown in Fig. 1b, c and d, respectively. Even though WRF misses detailed patterns as in the SAR image (e.g., streaks and waves), the farm wake patterns are consistent. Comparing the wind speeds in the wake shadows and the surrounding 
(a)

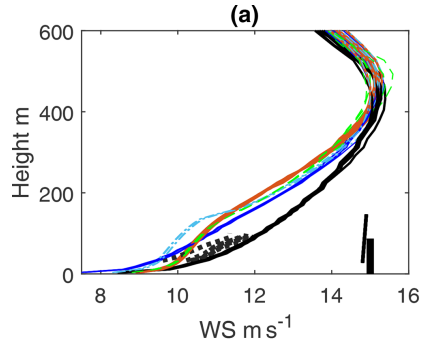

(c)
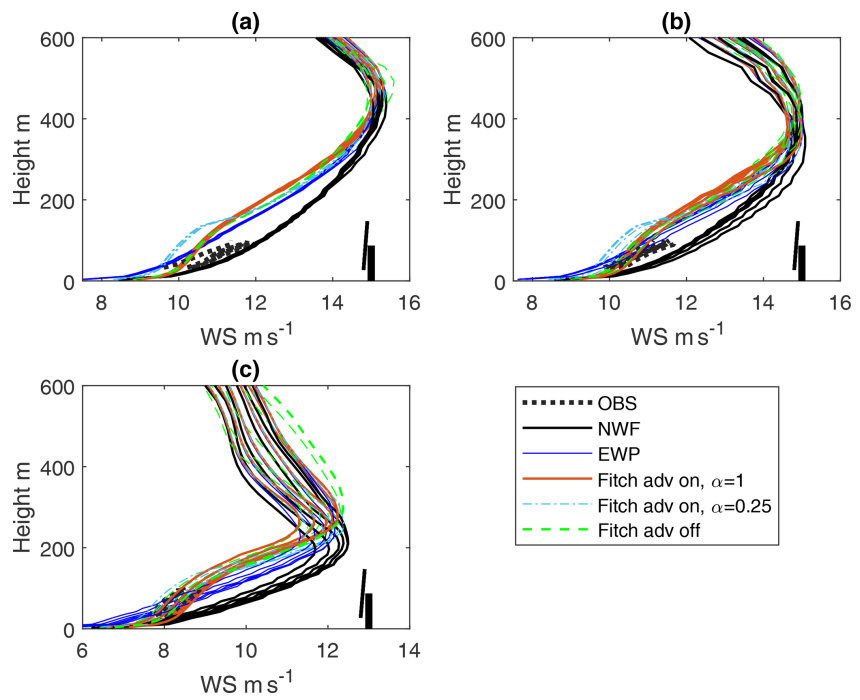

Figure 6. Wind profiles measured (OBS) and modeled (NWF, EWP, Fitch-on-1, Fitch-on-0.25, Fitch-off) at FINO 1 station on 14 October: (a) $10 \mathrm{~min}$ profiles between 14:00 and 15:00; (b) $10 \mathrm{~min}$ profiles from 15:00-16:00; (c) 10 min profiles from 20:00-21:00. The corresponding turbine hub height and the rotor area from the upwind farm Borkum Riffgrund 1 are illustrated in black.

Table 5. Differences between measurements and simulated wind speed time series at $100 \mathrm{~m}$ at FINO 1 between 12:00 and 24:00 on 14 October in terms of mean deficit, standard deviation of the difference and absolute difference. Positive values mean that the measured values are larger.

\begin{tabular}{lrrr}
\hline Denotation & $\langle\Delta U\rangle \mathrm{m} \mathrm{s}^{-1}$ & $\mathrm{SD} \mathrm{m} \mathrm{s}^{-1}$ & $\langle|\Delta U|\rangle \mathrm{m} \mathrm{s}^{-1}$ \\
\hline EWP & -0.21 & 0.57 & 0.50 \\
Fitch-on-0.25 & 0.59 & 0.56 & 0.65 \\
Fitch-on-1 & 0.22 & 0.50 & 0.43 \\
Fitch-off & 0.30 & 0.46 & 0.44 \\
NWF & -1.45 & 0.59 & 1.45
\end{tabular}

free stream, both SAR data and WRF output suggest a wind reduction of about $1.5-2 \mathrm{~m} \mathrm{~s}^{-1}$, with the wind speeds in the farm wakes in the range of $7-8 \mathrm{~m} \mathrm{~s}^{-1}$ and the free stream wind speeds in the range of $9-10 \mathrm{~m} \mathrm{~s}^{-1}$. To make the wind farm wake effect more visible, the differences of the wind speed at $10 \mathrm{~m}$ between EWP and NWF, between Fitch-off and NWF-off, between Fitch-on-1 and NWF, and between Fitch-on-0.25 and NWF are shown in Fig. 9. Here one can see that the wake-caused wind speed reduction at $10 \mathrm{~m}$ is about $2.5 \mathrm{~m} \mathrm{~s}^{-1}$ inside the farm, and a reduction of $0.5 \mathrm{~m} \mathrm{~s}^{-1}$ can extend between 10 and $100 \mathrm{~km}$ downwind, superimposing with wakes from other wind farms. At 17:17, the SAR $10 \mathrm{~m}$ wind speed at the FINO 1 site is about $8 \mathrm{~m} \mathrm{~s}^{-1}$, and the WRF outputs from both the Fitch and EWP schemes are also about $8 \mathrm{~m} \mathrm{~s}^{-1}$. Note that in a short distance downwind of the wind farms, the surface wind at $10 \mathrm{~m}$ from the Fitch scheme suggests a slight speedup; see the brighter color in the farm wake shadows in Fig. 1b and the white color in Fig. 9b, c and $\mathrm{d}$. This speedup is a phenomenon that deserves further investigation (Djath et al., 2018), but it is beyond the scope of this study. Moreover, all four wind farm simulations in Fig. 9 suggest the presence of reduced wind speed in front of the farms. This is referred to as the global blockage effect (Bleeg et al., 2018; Schneemann et al., 2021). Such an effect is most obvious for wind farms with free upstream flow, and it is more obvious in the Fitch simulations.

The transect-flight data over transect "a" are plotted in Fig. 10 for wind speed at $250 \mathrm{~m}(\mathrm{a}, \mathrm{c})$ and TKE (b, d) at $250 \mathrm{~m}$. To improve the visibility of individual model scenarios, Fig. 10a and b compare measurements, NWF, EWP and Fitch-off, and Fig. 10c and d compare measurements, Fitchon-1, Fitch-on-025 and Fitch-off. There are altogether six flights over transect "a" between approximately 14:20 and 16:10 (Table 1), and each lasted approximately $10 \mathrm{~min}$. We averaged the flight data over a spatial distance of both $2 \mathrm{~km}$ (same as the WRF spatial resolution) and $1.5 \mathrm{~km}$ (same as in S2020). The results of the two averaging distances are similar; the one using $1.5 \mathrm{~km}$ provides slightly more fluctuation. In Fig. 10 we only show the results using $2 \mathrm{~km}$. The corresponding model data at $250 \mathrm{~m}$ over transect red in Fig. 3 from 14:00 to 16:00, covering the flight periods, are plotted. The modeled data are $10 \mathrm{~min}$ instantaneous values plotted every half hour. Based on Fig. 10a and c, compared to the ambient flow, there is a deficit in wind speed at $250 \mathrm{~m}$ above the wind farm Godewind 1 due to wind farm effects. Such a wind deficit is almost $3 \mathrm{~m} \mathrm{~s}^{-1}$ in the flight data, only about $2 \mathrm{~m} \mathrm{~s}^{-1}$ in the modeled data using EWP and about $3 \mathrm{~m} \mathrm{~s}^{-1}$ in Fitchon-1, with a slightly smaller reduction for Fitch-off and an even smaller reduction for Fitch-adv-0.25.

As a result of the wind farm parameterizations, above the wind farm high TKE values are observed when compared with ambient values, which are almost zero (Fig. 10b and d). When no wind farms are included in the modeling, there is no systematic difference in TKE across transect "a"; see the black curves in Fig. 10b. Parameterizations of the wind farms result in increased TKE over the farm. At $250 \mathrm{~m}$, the Fitch-on-1 scheme provides TKE inside the range of the measured values, though with large underestimation at the southern edge of the farm and with comparable magnitude at the northern edge of the farm. The profiles at point A (Fig. 7b), which is approximately in the center of transect "a" and transect red (Fig. 3), show that the TKE values are highest close to hub height and decrease above it. At point A, the TKE values simulated by the Fitch-on- 1 and Fitch-off schemes are about $2.1-2.3 \mathrm{~m}^{2} \mathrm{~s}^{-2}$ at rotor top height, which is about $40 \%$ higher than the values at $250 \mathrm{~m}$. For transect "a", the TKE values from the EWP scheme are considerably smaller, being only about $1 / 3-1 / 4$ of the values from the Fitch scheme, and are thus significantly underestimated compared to the flight measurements. The overall TKE magnitudes across the transect from Fitch-on-1 and Fitch-off are 
(a)

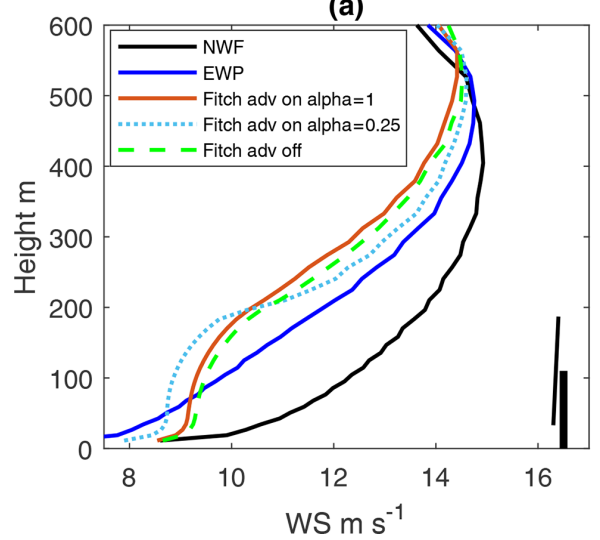

(b)

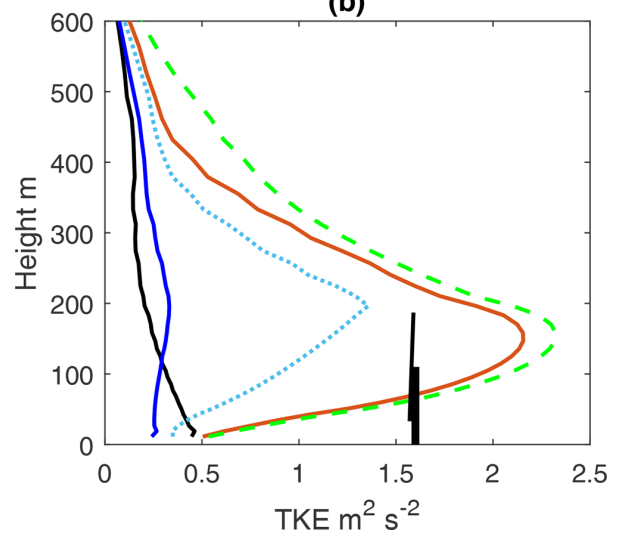

Figure 7. Modeled vertical profiles at point A (see Fig. 3) over the Godewind 1 wind farm at 15:00 on 14 October. (a) Wind speed; (b) TKE. The corresponding turbine hub height and the rotor area are illustrated in black.

(a)

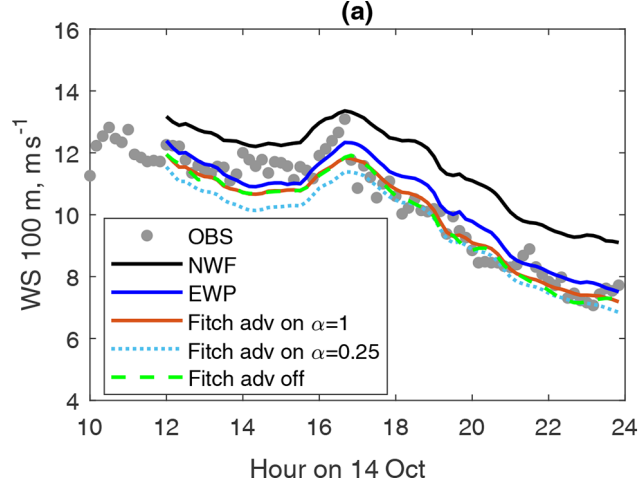

(b)

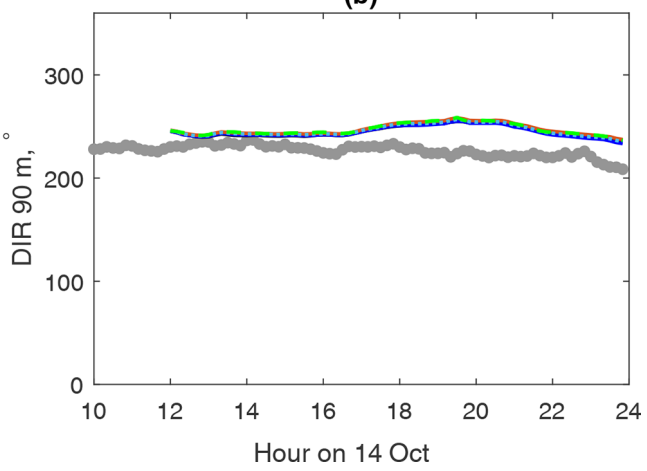

Figure 8. Measured and modeled time series at FINO 1 on 14 October 2017: (a) wind speed at $100 \mathrm{~m}$ and (b) wind direction at $90 \mathrm{~m}$ using the Fitch and EWP schemes, as well as the no farms option (NWF).

also comparable. Due to the activated TKE advection, Fitchon-1 provides a more even distribution across the transect compared to Fitch-off. Fitch-on-025, which also shows the even distribution of TKE across the transect, has significantly lower values of TKE compared to Fitch-on-1, Fitch-off and measurements.

One can notice the speedup in the flow in the flight measurements on the southern edge of the farm in Fig. 10a and c, as also pointed out in S2020; see the bump of wind speed at $250 \mathrm{~m}$ at latitudes before $54^{\circ} \mathrm{N}$. WRF does not capture this phenomenon with either scheme. The abrupt increase in TKE in the same area (Fig. 10b) is likely related to this flow acceleration and is also missing in the WRF results.

The vertical distributions of the wind speed and TKE along transect "a" are shown in contour lines in Fig. 11 as latitude (from south to north) versus height at 15:30 for both EWP and three Fitch simulations as an example. The LLJs are visible here in Fig. 11 (left column), with the wind speed maximum height between $\sim 200$ and $500 \mathrm{~m}$. The largest difference in the wind speed between the Fitch and EWP schemes is over the farm beneath the rotor top, with Fitch simulating on average larger wind speed reductions from the wind farm wake effect (Fig. 11a and c, e, g).

The right column in Fig. 11 shows that the largest TKE values are located at a height between hub height and rotor top. The three Fitch simulations correspond to several times larger TKE values than the EWP scheme, with the largest difference over the wind farm area. An increase in TKE is notable up to double the height of the rotor top. The maximum TKE values are largest with Fitch-off; they are slightly smaller with Fitch-on-1 and significantly smaller with Fitchon- 0.25 .

Outside the farm area and even in the wake region, the EWP and Fitch-off schemes provide similar wind speed and TKE values; see, for example, Fig. 12, which is for transect purple (Fig. 3b, with longitude approximately $7.2^{\circ} \mathrm{E}$ ). This resemblance is not given when turbine-induced TKE is advected downwind of the farm such as in Fitch-on-1 and Fitch-on-0.25. Compared to Fitch-off, in the far-wake region, TKEs from Fitch-on- 1 and Fitch-on- 0.25 are larger above $200 \mathrm{~m}$, which is above the Godewind 1 turbine hub height; see the right column of Fig. 12. 

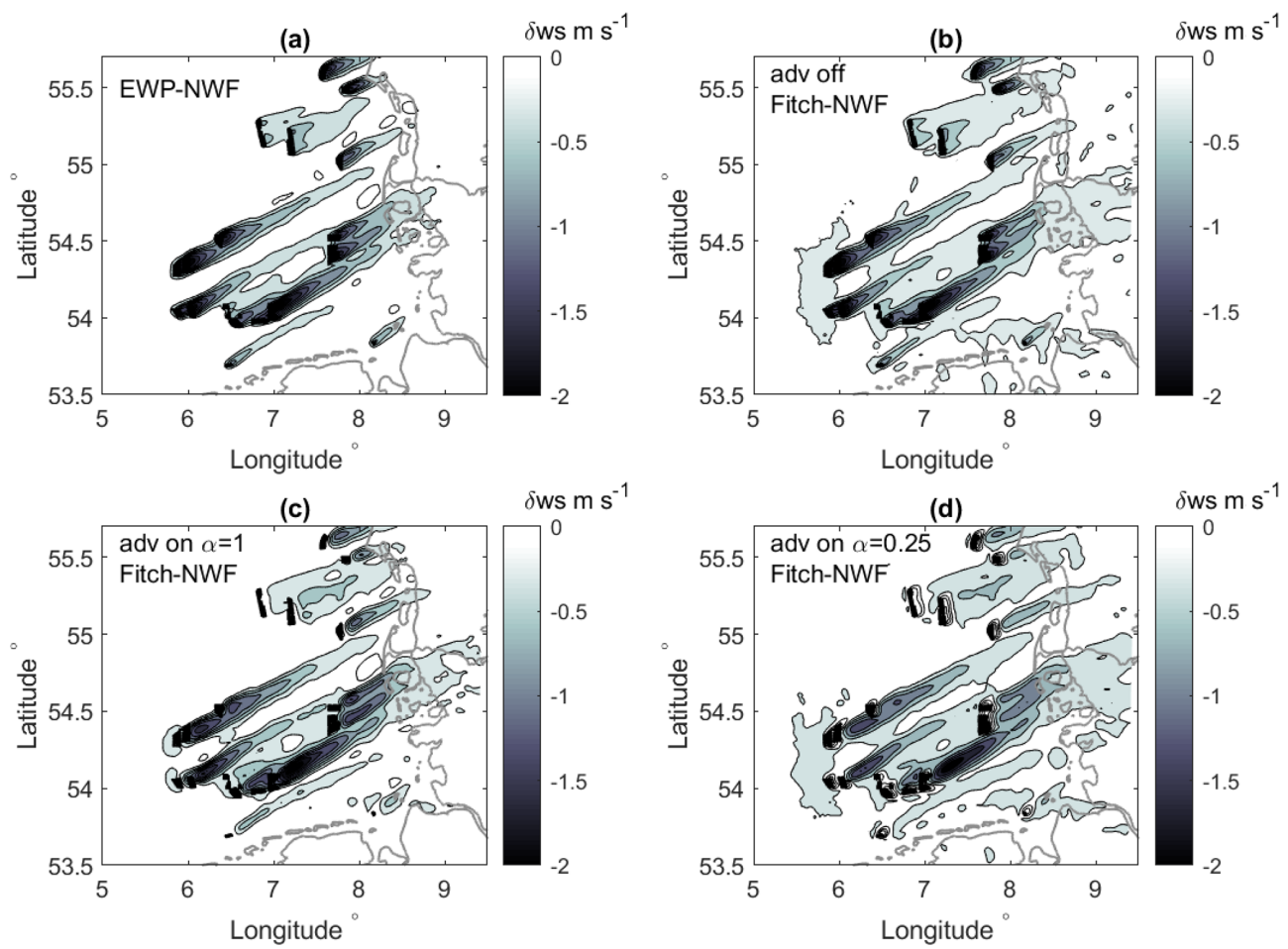

Figure 9. Wind speed deficit $\left(\mathrm{m} \mathrm{s}^{-1}\right)$ at about $10 \mathrm{~m}$ at 17:00 on 14 October 2017, corresponding to the SAR image as in Fig. 1. (a) Deficit between EWP and NWF; (b) deficit between Fitch-off and NWF; (c) deficit between Fitch-on-1 and NWF; (d) deficit between Fitch-on-025 and NWF.

These characteristics can also be seen in the horizontal spatial distribution of the wind speed (Fig. 13) and TKE (Fig. 14) at $250 \mathrm{~m}$ over the wind farm cluster with the Godewind 1 farm in the domain center. The patterns of spatial distribution of wind speed are consistent with the four plots in Fig. 13, though EWP shows an overall smaller wind speed reduction downwind of the farm and Fitch-on-1 corresponds to an overall larger reduction when compared to the rest. For the TKE, when TKE advection is turned off, farminduced TKE is mostly above the wind farm (Fig. 14b, Fitchoff). When the advection is turned on, the high TKE values are transported downwind of the farm in the mean wind direction in Fig. 14c (Fitch-on-1) and d (Fitch-on-0.25). TKE in the EWP scheme, as a function of the wind shear, follows the mean flow. When the TKE advection is turned off, EWPoff provides a similar spatial distribution as in Fig. 14a, only with the maximum TKE at slightly less distance away from the Godewind 1 farm (not shown).

\section{Discussion and conclusions}

For the first time, calculations of both wind speed and TKE from two explicit wind farm parametrization schemes (Fitch and EWP) in WRF are compared and verified through a case study, thanks to open-access high-frequency flight data over and around the wind farm Godewind 1 (Bärfuss et al., 2019a) and FINO 1 measurements. This study thus complements S2020 wherein only the Fitch scheme was used to model the wind farm wake. Additionally, we used a WRF version into which the turbine-induced TKE is correctly integrated and advected with the overall TKE field, following Archer et al. (2020).

The farm wake effect is discussed here with a variety of measurements: in the FINO 1 mast measurements shown as a vertical wind profile and time series, in the SAR $10 \mathrm{~m}$ wind speed shown as a spatial distribution, and in the flight data shown as a cross-wind farm transect distribution of wind speed and TKE at $250 \mathrm{~m}$. The WRF modeling with the two farm parametrization schemes EWP and Fitch captures these observed farm wake effects consistently in terms of wind speed, but with some noticeable differences. In the vertical wind profiles at FINO 1, when compared to the EWP scheme, the wind speed deficit due to the wind farm wakes using the Fitch scheme is more centered and more pronounced around the hub height and rotor area, which is visible as a kink in the profile. In the EWP scheme, due to the sub-grid-scale vertical wake expansion, the wind deficit is more spread out and smooth over the rotor area. The larger wind speed deficit in association with the Fitch scheme beneath the rotor top height is also visible over the wind farm and in the wake areas. The flight data suggest a flow acceleration on the southern side of the wind farm Godewind 1 accompanying the 
(a)

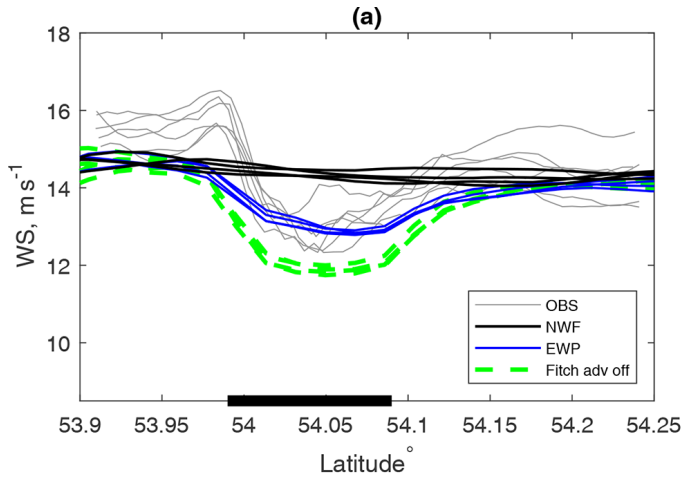

(c)

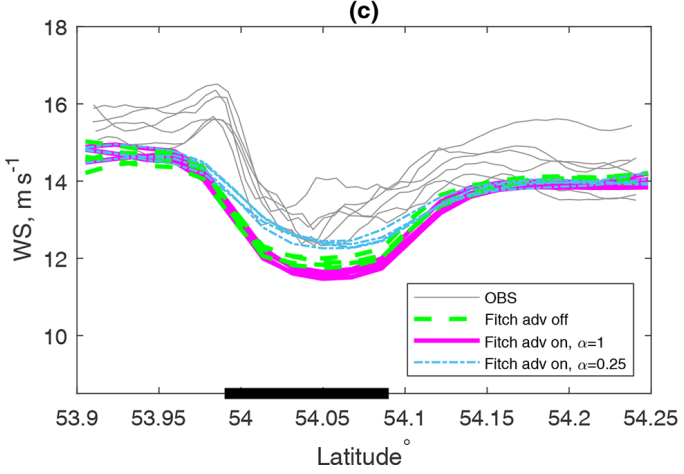

(b)

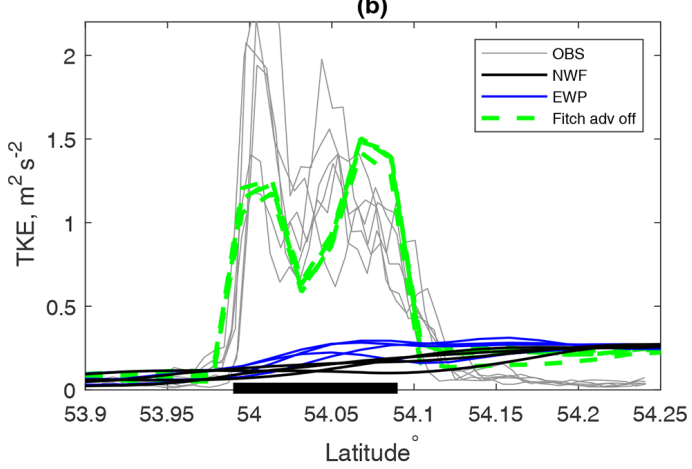

(d)

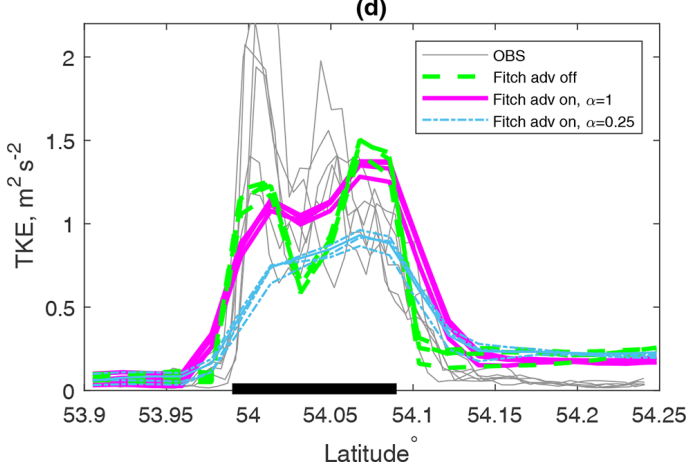

Figure 10. (a, c) Transect "a" distribution of wind speed at $250 \mathrm{~m}$ as a function of latitude between 14:00 and 16:00 on 14 October 2017, both observed (OBS) and modeled (every $30 \mathrm{~min}$ ). (b, d) Similar to (a, c) but for TKE. The observed values are the flight data averaged over a distance of $2 \mathrm{~km}$. The modeled values are from the use of the Fitch, EWP and no wind farm (NWF) schemes. The wind farm is indicated on the $x$ axis by a thick black line.

flow from the southwest. This acceleration, however, is not captured in WRF. It is expected that a high-fidelity model is needed to further investigate this feature.

Even though the modeled wind speeds are comparable using the two schemes, the results for TKE are significantly different. The Fitch scheme, having TKE contributions from both the shear and an explicit term related to the turbine power and thrust coefficients, provides TKE values several times larger than those from the EWP scheme. In addition, WRF misses the flow acceleration south of the farm, and it underestimates TKE in the adjacent wind farm area. At the northern part of the farm, the modeled TKE values using the Fitch scheme are of comparable magnitude with respect to the measurements. TKE values from the EWP scheme are significantly underestimated. This suggests that turbineinduced TKE does not only develop from the shear, as assumed in the EWP scheme, but instead an explicit source is required.

Most recent studies in the literature have recommended deactivating TKE advection when using the Fitch scheme based on simulations with WRF containing a code bug that incorrectly treated the turbine-induced TKE in the advection scheme and incorrectly neglected electromechanical losses, as pointed out in Archer et al. (2020). The Archer et al. (2020) analysis suggests that the two issues interact with each other, causing compensating errors. This generated TKE values in a realistic range, which might be the reason that the issues were not identified before. S2020 found that, with the bug, their simulation is in better agreement with measurements with advection turned off.

All results presented here are from the bug-fixed version of WRF, following Archer et al. (2020). Accordingly, we tested two correction factors, $\alpha=0.25$ and 1. The Archer et al. (2020) study recommended using $\alpha$ less than 1, e.g., 0.25 , according to their verification with large eddy simulations. This, however, is not supported by the current study. Using $\alpha=0.25$ does not always improve the results, as can be seen in the comparison with measurements from FINO 1 and with the flight data over the Godewind 1 farm. With TKE advection turned on in Fitch, TKE is no longer concentrated above the wind farm but advected with the mean flow, similar to EWP in which the shear-induced turbulence naturally follows the mean flow advection. With TKE advection turned on and $\alpha=1$, the results for the mean wind speed field are quite similar to those with TKE advection turned off. While using $\alpha=0.25$ gives a similar spatial distribution of wind speed and TKE, it gives quite different magnitudes of speed reduction and TKE values. Due to lack of measurements, it re- 
(a)

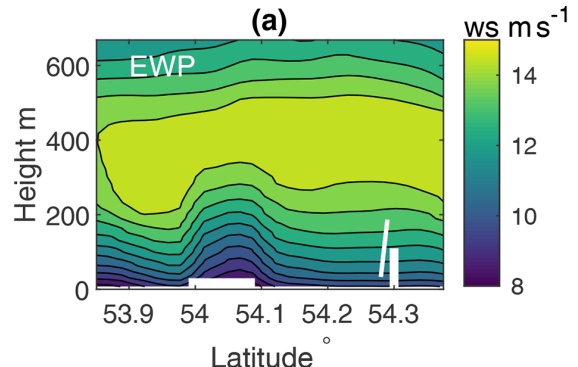

(c)

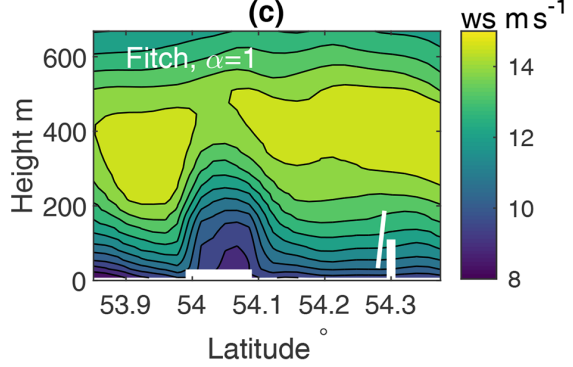

(e)

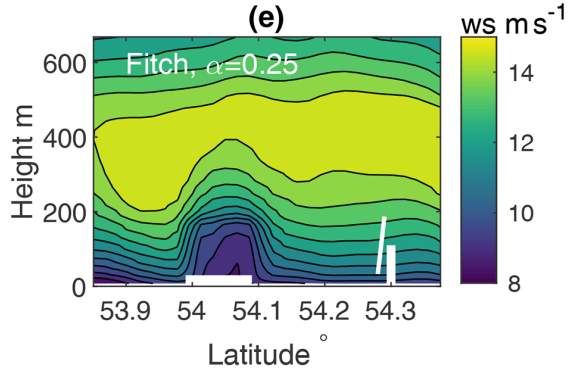

(g)

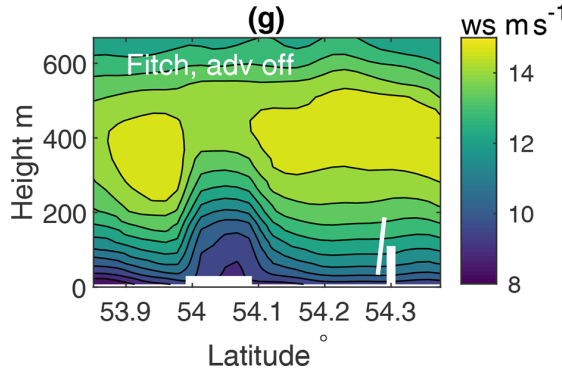

(b)

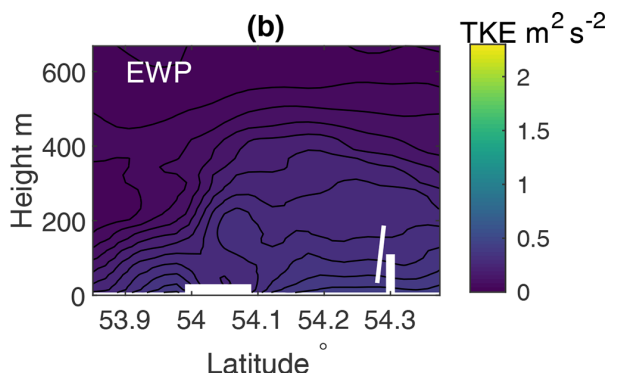

(d)

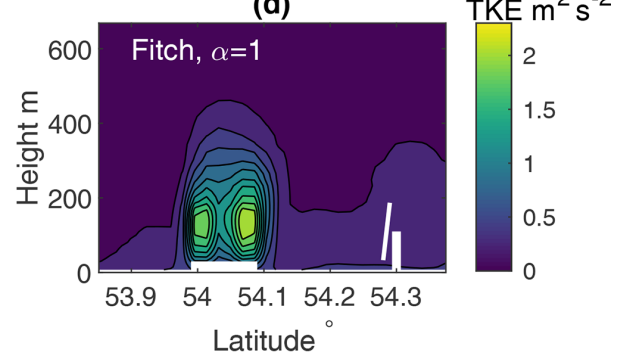

(f)

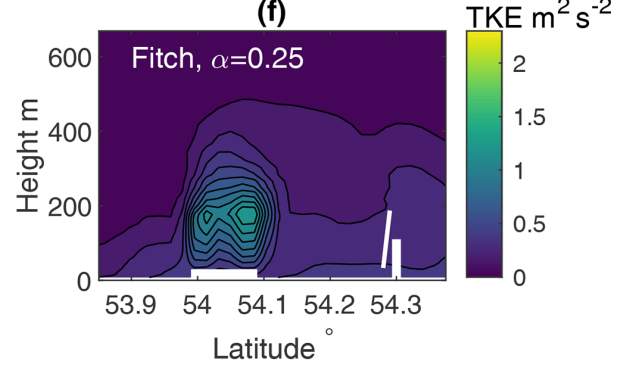

(h)

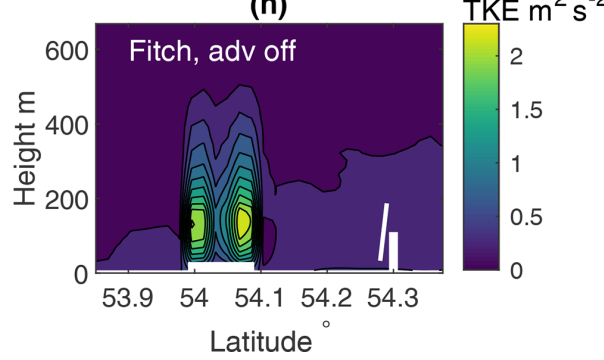

Figure 11. Distribution of wind speed (left column) and TKE (right column) over transect red (at longitude $7.02^{\circ} \mathrm{E}$ ) at $15: 30$ on 14 October 2017; $x$ axis: south-north, $z$ axis: height. Row-1: EWP. Row-2: Fitch-on-1. Row-3: Fitch-on-025. Row-4: Fitch-off. The wind farm is indicated on the $x$ axis by a thick white line, and the corresponding turbine is illustrated in white.

mains inconclusive how much the inclusion of farm-induced TKE advection improves the results and what are the correct $\alpha$ values to use. More measurements and more meteorological conditions are needed for further investigation.

Since most studies in the literature using the Fitch scheme are affected by the code bug, here we also briefly examine some results from WRF before the bug fix. Figure 15 shows the profiles at point A, similar to Fig. 7, but also including a simulation with WRF-Fitch with the bug and advection turned on (the only option for $\alpha$ is 1 in that version); the results are very different for both wind speed and TKE compared to the bug-fixed version with $\alpha=1$. This result suggests that the effect of this bug is not negligible.
The impact of deactivated TKE advection was also tested in connection with the simulation with no farms (NWF-off) and the EWP scheme (EWP-off). Compared to NWF and EWP, the differences in the wind field are not systematic but are shown to be random noises with NWF-off and EWPoff (not shown). One can notice that TKE related to turbineaffected shear travels slightly further in EWP than EWP-off. The overall effect on the wind speed and TKE is marginal and does not change the findings in the study.

The simulations here also suggest the presence of a global blockage effect when the flow approaches the wind farms. Future studies are required to understand if such an effect 


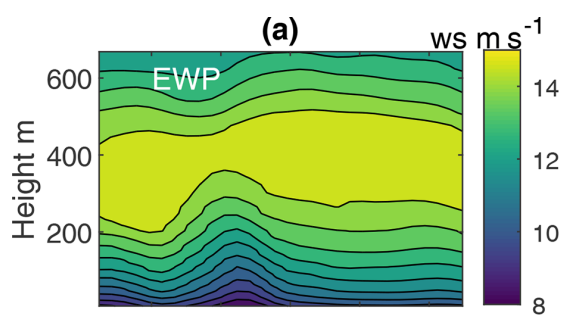

$\begin{array}{lllll}54 & 54.1 & 54.2 & 54.3 & 54.4\end{array}$

Latitude

(c)

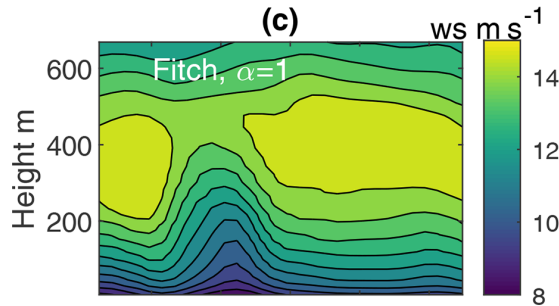

$\begin{array}{lllll}54 & 54.1 & 54.2 & 54.3 & 54.4\end{array}$

Latitude ${ }^{\circ}$

(e)

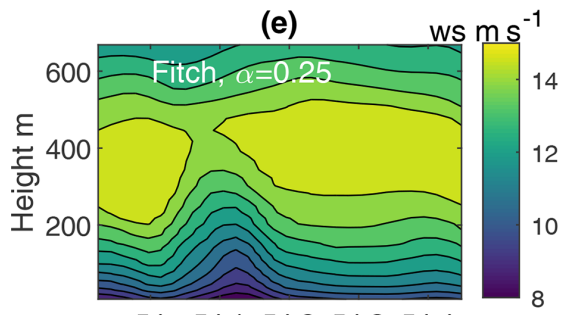

$\begin{array}{lllll}54 & 54.1 & 54.2 & 54.3 & 54.4\end{array}$

Latitude

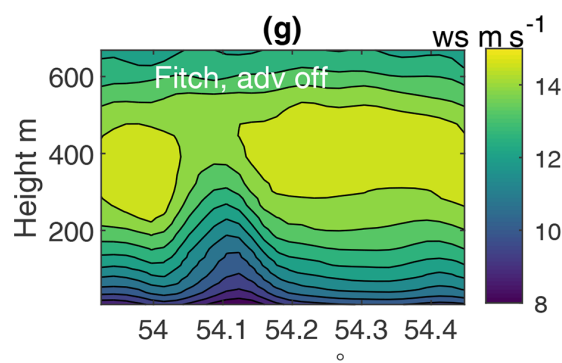

Latitude

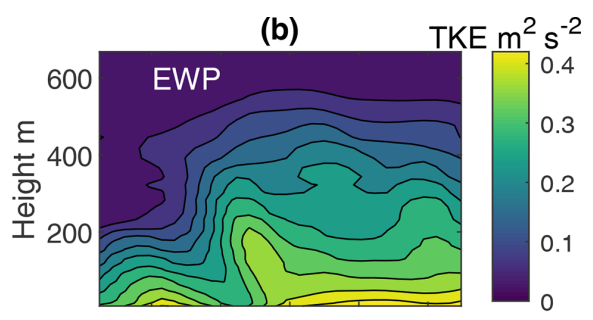

$54 \quad 54.154 .2 \quad 54.3 \quad 54.4$

Latitude

(d)

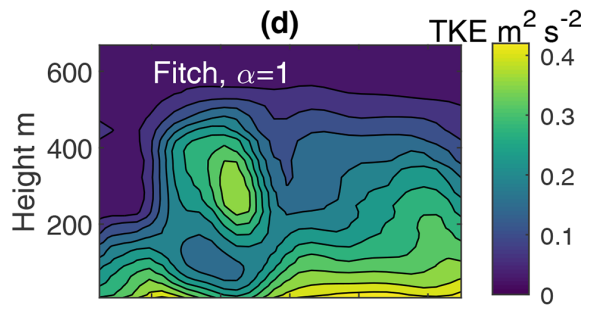

$\begin{array}{lllll}54 & 54.1 & 54.2 & 54.3 & 54.4\end{array}$

Latitude
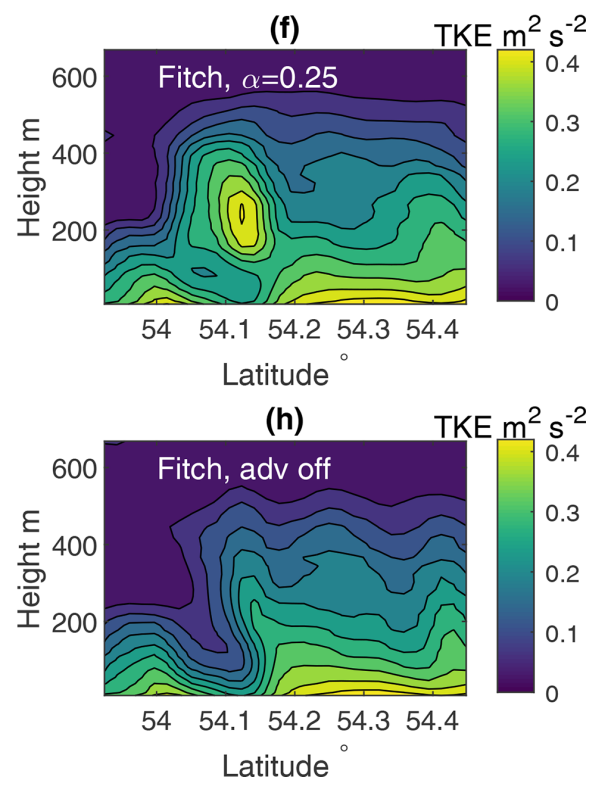

Figure 12. Similar to Fig. 11, but for transect purple (at longitude $7.2^{\circ} \mathrm{E}$ ) downwind of wind farms at 15:30 on 14 October.

is accurately captured and which scheme describes such an effect better.

The studied case becomes even more interesting due to the presence of LLJs, as LLJs are a common phenomenon in this area of the North Sea. Numerical modeling studies of wind energy usually address the rich resource in connection with LLJs, though few have included a wind farm wake effect. This case study shows an overestimation of the $100 \mathrm{~m}$ wind speed by approximately $1.45 \mathrm{~m} \mathrm{~s}^{-1}$ at FINO 1 when ignoring the wind farm effect in the WRF modeling, accounting for $11-20 \%$ of the mean wind speed during this simulation period. At the same time, measurements and modeling at FINO 1 suggest that the wind speed profile in the presence of LLJs is modified by the presence of wind farm wakes. The wind farm wakes lead to a reduced wind speed up to the jet nose, a higher jet nose and a higher wind shear beneath the jet nose. This upward shift of the jet nose in the presence of a wind farm was also modeled in different LES studies (Sharma et al., 2017; Abkar et al., 2016).

\section{Conclusions}

It is important to take the wind farm wake effect into account when calculating LLJ wind speeds in areas with wind farms. LLJ structures are affected by the presence of wind farms. The WRF model with both the Fitch and EWP schemes can capture the wind speed field rather well and consistently. It 

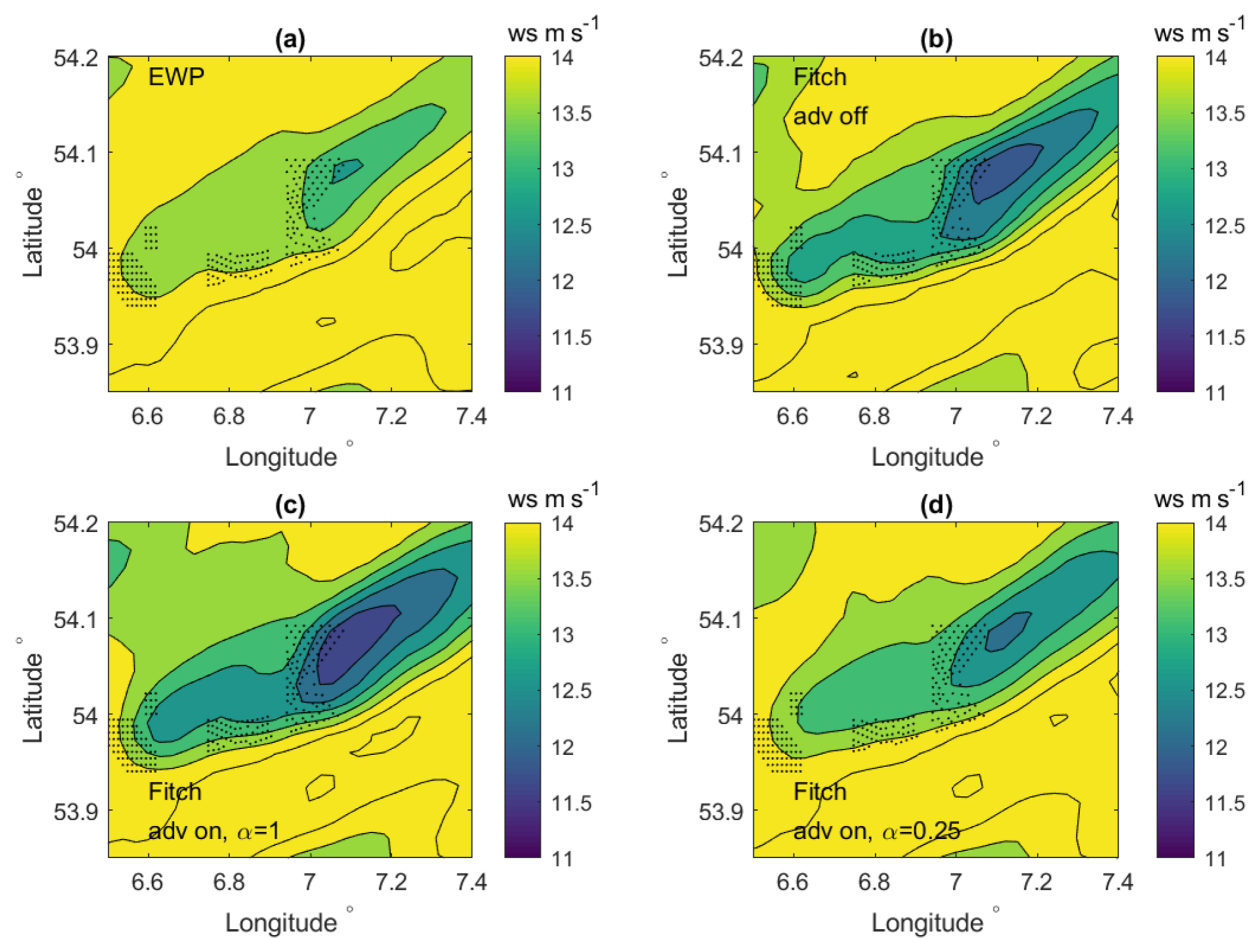

Figure 13. Spatial distribution of wind speed at $250 \mathrm{~m}$ from the WRF model on 14 October 2017 at 15:30 (a) using the EWP scheme, (b) the Fitch scheme with advection off (Fitch-off), (c) the Fitch scheme with advection on and $\alpha=1$ (Fitch-on-1), and (d) the Fitch scheme with advection on and $\alpha=0.25$ (Fitch-on-0.25).
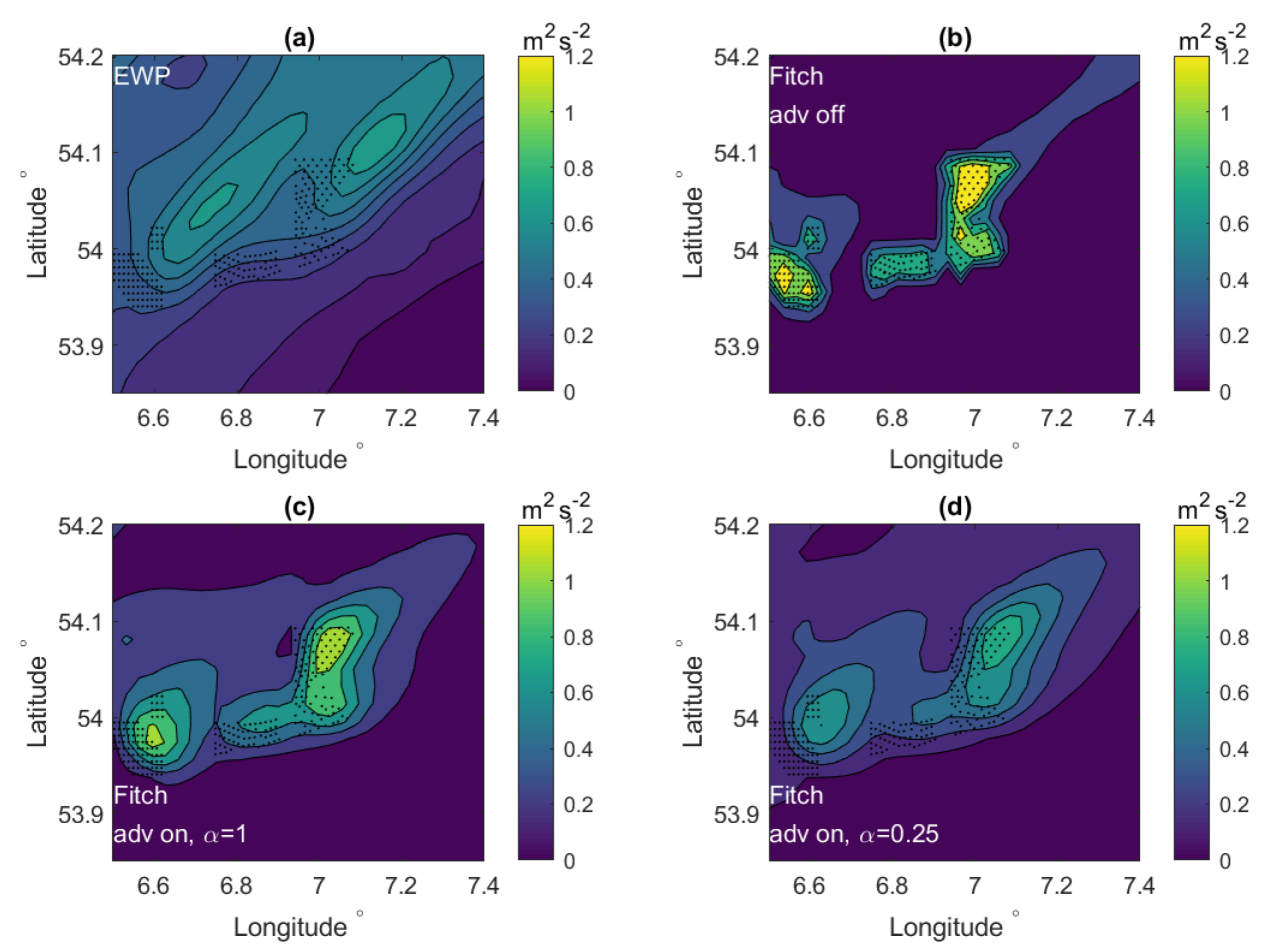

Figure 14. Spatial distribution of TKE at $250 \mathrm{~m}$ from the WRF model on 14 October 2017 at 15:30 (a) using the EWP scheme, (b) the Fitch scheme with advection off (Fitch-off), (c) the Fitch scheme with advection on and $\alpha=1$ (Fitch-on-1), and (d) the Fitch scheme with advection on and $\alpha=0.25$ (Fitch-on-0.25). 

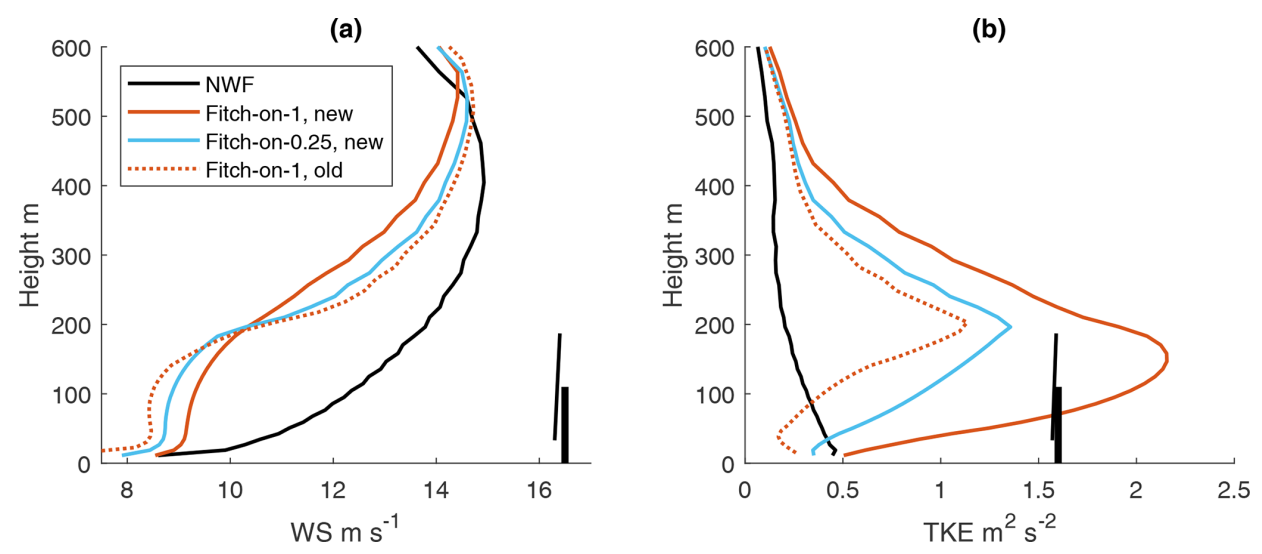

Figure 15. Similar to Fig. 7, except for EWP, Fitch-on-1, Fitch-on-0.25 and Fitch-old.

remains inconclusive which scheme is better at describing the wind field, as sometimes the EWP scheme outperforms the Fitch scheme, and some other times it is the other way around. It also remains inconclusive which correction factor should be used in connection with the turbine-induced TKE generation in the Fitch scheme: we only tested two factors (1 and 0.25 ) here and we observe a better performance when using $\alpha=1$ than $\alpha=0.25$, which does not support the conclusion from Archer et al. (2020). TKE from the EWP scheme is significantly underestimated compared to the flight measurements. This suggests that an explicit turbine-induced source of TKE should be included in addition to the shear-generated TKE. Neither scheme can capture the flow acceleration along the farm edge.

This case study shows typical features of wind farm wakes in the presence of LLJs using the most common modeling approaches. It raises issues that have not been addressed in the literature, namely the interaction of wind farm wakes and LLJs. It also clearly shows the need for improvements of turbine-induced TKE calculations using the wind farm parameterizations in WRF. This study therefore serves as a starting point for a more systematic study of similar conditions.

Code and data availability. The WRF model code is publicly available at https://github.com/wrf-model/WRF (last access: 29 May 2021). The WRF input files and the source code for the wind farm parameterizations of Volker et al. (2015) as well as of Fitch et al. (2012) with bug fix by Archer et al. (2020) are permanently indexed at https://doi.org/10.5281/zenodo.4668613 (Larsén and Fischereit, 2021). Updates for EWP will be made available at https://gitlab.windenergy.dtu.dk/WRF/EWP (DTU Wind Energy, 2021a). The SAR data are available from https://satwinds.windenergy.dtu.dk/ (DTU Wind Energy, 2021b). The FINO 1 measurements can be assessed from http://fino.bsh.de/ (Bundesamt für Seeschifffahrt und Hydrographie, 2021). The flight data are available at https://doi.org/10.1594/PANGAEA.902845 (Bärfuss et al., 2019a). The OSTIA data are available from
http://my.cmems-du.eu/motu-web/Motu (CMEMS, 2021). ERA5 data were downloaded from https://doi.org/10.24381/cds.bd0915c6 (ERA5, 2021). Data and scripts required to reproduce the analysis in this study are also shared in the above Zenodo record at https://doi.org/10.5281/zenodo.4668613 (Larsén and Fischereit, 2021).

Author contributions. XL outlined the paper. XL and JF ran the simulations, performed the data analysis and wrote the draft.

Competing interests. The authors declare that they have no conflict of interest.

Acknowledgements. This study is supported by the ForskEL/EUDP OffshoreWake project (PSO-12521/EUDP 64017-0017). We thank the open-source platform at https://doi.org/10.1594/PANGAEA.902845 (Bärfuss et al., 2019a) for the flight data. We thank the Federal Maritime and Hydrographic Agency (BSH) for providing measurements at the FINO 1 station. We thank our colleagues Jake Badger, Andrea Hahmann and Rogier Floors for discussions. Data processing and visualization for this study were in part conducted using the Python programming language and involved the use of the following software packages: NumPy (van der Walt et al., 2011), pandas (McKinney, 2010), xarray (Hoyer and Hamman, 2017) and Matplotlib (Hunter, 2007). The colors for the line plot have bee selected through the "Color Cycle Picker" at https://github.com/mpetroff/color-cycle-picker (last access: 29 May 2021). The authors are grateful for the tools provided by the open-source community.

Financial support. This research has been supported by the Danish ForskEL/EUDP (grant no. PSO-12521/EUDP 64017-0017).

Review statement. This paper was edited by Simon Unterstrasser and reviewed by Simon Siedersleben and one anonymous referee. 


\section{References}

4Coffshore: Global Offshore Wind Farms, available at: http://www. 4coffshore.com, last access: 29 May 2021.

Abkar, M., Sharifi, A., and Porté-Agel, F.: Wake flow in a wind farm during a diurnal cycle, J. Turbulence, 17, 420-441, https://doi.org/10.1080/14685248.2015.1127379, 2016.

Archer, C. L., Wu, S., and Ma, Y.: Two corrections for turbulent kinetic energy generated by wind farms in the WRF model, Mon. Weather Rev., 148, 4823-4835, https://doi.org/10.1175/MWRD-20-0097.1, 2020.

Badger, J., Imberger, M., Volker, P., A. Kleidon, S. G., and Minz, J.: Making the most of offshore wind - reevaluating the potential of offshore wind in the German North Sea, available at: https://www.agora-energiewende.de/en/ publications/making-the-most-of-offshore-wind/ (last access: 29 May 2021), 2020.

Bärfuss, K., Hankers, R., Bitter, M., Feuerle, T., Schulz, H., Rausch, T., Platis, A., Bange, J., and Lampert, A.: In-situ airborne measurements of atmospheric and sea surface parameters related to offshore wind parks in the German Bight, PANGAEA, https://doi.org/10.1594/PANGAEA.902845, 2019a.

Bärfuss, K., Hankers, R., Bitter, M., Feuerle, T., Schulz, H., Rausch, T., Platis, A., Bange, J., and Lampert, A.: Insitu airborne measurements of atmospheric and sea surface parameters related to offshore wind parks in the German Bight, Flight 20171014_flight39, PANGAEA, https://doi.org/10.1594/PANGAEA.903088, 2019b.

Bleeg, J., Purcell, M., Ruisi, R., and Traiger, E.: Wind farm blockage and consequences of neglecting its impact on energy production, Energies, 11, 1609, https://doi.org/10.3390/en11061609, 2018.

Bundesamt für Seeschifffahrt und Hydrographie: FINO 1 database, available at: http://fino.bsh.de/, last access: 29 May 2021.

Bundesnetzagentur: Turbines positions, available at: https://www.bundesnetzagentur.de/SharedDocs/Downloads VDE/Sachgebiete/Energie/Unternehmen_Institutionen/ ErneuerbareEnergien/ZahlenDatenInformationenIVVOeFF_ Registerdaten/2019_01_Veroeff_RegDaten.html (last access: 19 March 2021), 2019.

Catton, M.: Climatological study of wakes from offshore wind farm clusters, Tech. Rep. DTU Wind Energy-M0361, Wind Energy Department, DTU, Roskilde, Denmark, available at: http://production.datastore.cvt.dk/ oafilestore?oid=5f23fcaed $9001 \mathrm{~d} 016 \mathrm{~b} 4 \mathrm{e} 226 \mathrm{~d} \&$ targetid= 5f23fcaed9001d016b4e2270 (last access: 19 March 2021), 2020.

CMEMS: OSTIA dataset, available at: http://my.cmems-du.eu/ motu-web/Motu, last access: 29 May 2021.

Djath, B., Schulz-Stellenfleth, J., and Canadillas, B.: Impact of atmospheric stability on X-band and C-band synthetic aperture radar imagery of offshore windpark wakes, J. Renew. Sustain. Ener., 10, 043301, https://doi.org/10.1063/1.5020437, 2018.

Donlon, C., Martin, M., Stark, J., Roberts-Jones, J., Fiedler, E., and Wimmer, W.: The operational sea surface temperature and sea ice analysis (OSTIA) system, Remote Sens. Environ., 116, 140-158, https://doi.org/10.1016/j.rse.2010.10.017, 2012.

Díaz, H. and Guedes Soares, C.: Review of the current status, technology and future trends of offshore wind farms, Ocean Eng.,
209, 107381, https://doi.org/10.1016/j.oceaneng.2020.107381, 2020.

Dörenkämper, M., Optis, M., Monahan, A., and Steinfeld, G.: On the Offshore Advection of Boundary-Layer Structures and the Influence on Offshore Wind Conditions, Bound.-Lay. Meteorol., 155, 459-482, https://doi.org/10.1007/s10546-015-0008-x, 2015.

DTU Wind Energy, EWP source codes, available at: https://gitlab. windenergy.dtu.dk/WRF/EWP, last access: 29 May 2021a.

DTU Wind Energy, Satellite wind database, available at: https: //satwinds.windenergy.dtu.dk/, last access: 29 May 2021b.

Emodnet: Wind Farms (Polygons), available at: https://www. emodnet-humanactivities.eu/search-results.php?dataname= Wind+Farms+(Polygons), (last access: 19 March 2021), 2020.

Energistyrelsen: Turbines positions, available at: https://ens.dk/service/statistik-data-noegletal-og-kort/ data-oversigt-over-energisektoren, (last access: 19 March 2021), 2020.

ERA5: ERA5 hourly data on pressure levels from 1979 to present, Copernicus Climate Change Service (C3S) Climate Data Store (CDS), https://doi.org/10.24381/cds.bd0915c6, last access: 19 March 2021.

Fischereit, J., Brown, R., Larsén, X. G., Badger, J., and Hawkes, G.: Review of mesoscale wind farm parameterisations and their applications, Bound.-Lay. Meteorol., accepted, 2021.

Fitch, A. C., Olson, J. B., Lundquist, J. K., Dudhia, J., Gupta, A. K., Michalakes, J., and Barstad, I.: Local and Mesoscale Impacts of Wind Farms as Parameterized in a Mesoscale NWP Model, Mon. Weather Rev., 140, 3017-3038, https://doi.org/10.1175/MWRD-11-00352.1, 2012.

Hersbach, H., Stoffelen, A., and de Haan, S.: An improved C-band scatterometer ocean geographical model function: CMOD5, J. Geophys. Res., 112, C03006, https://doi.org/10.1029/2006JC003743, 2007.

Hoyer, S. and Hamman, J.: xarray: N-D labeled Arrays and Datasets in Python, J. Open Res. Softw., 5, p. 10, https://doi.org/10.5334/jors.148, 2017.

Hunter, J. D.: Matplotlib: A 2D Graphics Environment, Comput. Sci. Eng., 9, 90-95, https://doi.org/10.1109/MCSE.2007.55, 2007.

Iacono, M. J., Delamere, J. S., Mlawer, E. J., Shephard, M. W., Clough, S. A., and Collins, W. D.: Radiative forcing by long-lived greenhouse gases: Calculations with the AER radiative transfer models, J. Geophys. Res., 113, 13013, https://doi.org/10.1029/2008JD009944, 2008.

Kain, J. S. and Fritsch, J. M.: Convective parameterization for mesoscale models: The Kain-Fritsch scheme, The representation of cumulus convection in numerical models, Meteor. Monogr. Am. Meteor. Soc., 24, 165-170, 1993.

Kalverla, P., Steeneveld, G.-J., Ronda, R., and Holtslag, A. A. M.: Evaluation of three mainstream numerical weather prediction models with observations from meteorological mast IJmuiden at the North Sea, Wind Energy, 22, 34-48, https://doi.org/10.1002/we.2267, 2019.

Lampert, A., Bärfuss, K., Platis, A., Siedersleben, S., Djath, B., Cañadillas, B., Hunger, R., Hankers, R., Bitter, M., Feuerle, T., Schulz, H., Rausch, T., Angermann, M., Schwithal, A., Bange, J., Schulz-Stellenfleth, J., Neumann, T., and Emeis, S.: In situ airborne measurements of atmospheric and sea surface parame- 
ters related to offshore wind parks in the German Bight, Earth Syst. Sci. Data, 12, 935-946, https://doi.org/10.5194/essd-12935-2020, 2020.

Langor, E. N.: Characteristics of Offshore Wind Farm Wakes and their Impact on Wind Power Production from Long-term Modelling and Measurements, Tech. Rep. DTU Wind Energy-M0315, 2019.

Larsén, X. G. and Fischereit, J.: A case study of wind farm effects using two wake parameterizations in WRF (V3.7.1) in the presence of low level jets, Zenodo, https://doi.org/10.5281/zenodo.4668613, 2021.

Lee, J. C. Y. and Lundquist, J. K.: Evaluation of the wind farm parameterization in the Weather Research and Forecasting model (version 3.8.1) with meteorological and turbine power data, Geosci. Model Dev., 10, 4229-4244, https://doi.org/10.5194/gmd-10-4229-2017, 2017a.

Lee, J. C. and Lundquist, J. K.: Observing and Simulating WindTurbine Wakes During the Evening Transition, Bound.-Lay. Meteorol., 164, 449-474, https://doi.org/10.1007/s10546-017-0257y, 2017b.

McKinney, W.: Data Structures for Statistical Computing in Python, in: Proceedings of the 9th Python in Science Conference, edited by: van der Walt, S. and Millman, J., available at: https://conference.scipy.org/proceedings/scipy2010/ pdfs/mckinney.pdf (last access: 27 October 2020), 2010.

Nakanishi, M. and Niino, H.: Development of an improved turbulence closure model for the atmospheric boundary layer, J. Meteorol. Soc. Jpn., 87, 895-912, 2009.

Nunalee, C. G. and Basu, S.: Mesoscale modeling of coastal lowlevel jets: implications for offshore wind resource estimation, Wind Energy, 17, 1199-1216, 2014.

Platis, A., Siedersleben, S. K., Bange, J., Lampert, A., Bärfuss, K., Hankers, R., Cañadillas, B., Foreman, R., Schulz-Stellenfleth, J., Djath, B., Neumann, T., and Emeis, S.: First in situ evidence of wakes in the far field behind offshore wind farms, Sci. Rep., 8, https://doi.org/10.1038/s41598-018-20389-y, 2018.

Pryor, S. C., Shepherd, T. J., Volker, P. J. H., Hahmann, A. N., and Barthelmie, R. J.: "Wind Theft" from Onshore Wind Turbine Arrays: Sensitivity to Wind Farm Parameterization and Resolution, J. Appl. Meteorol. Clim., 59, 153-174, https://doi.org/10.1175/jamc-d-19-0235.1, 2020.

Schneemann, J., Theuer, F., Rott, A., Dörenkämper, M., and Kühn, M.: Offshore wind farm global blockage measured with scanning lidar, Wind Energ. Sci., 6, 521-538, https://doi.org/10.5194/wes6-521-2021, 2021.

Sharma, V., Parlange, M. B., and Calaf, M.: Perturbations to the Spatial and Temporal Characteristics of the DiurnallyVarying Atmospheric Boundary Layer Due to an Extensive Wind Farm, Bound.-Lay. Meteorol., 162, 255-282, https://doi.org/10.1007/s10546-016-0195-0, 2017.

Shepherd, T., Barthelmie, R. J., and Pryor, S. C.: Sensitivity of Wind Turbine Array Downstream Effects to the Parameterization Used in WRF, J. Appl. Meteorol. Clim., 59, 333-361, https://doi.org/10.1175/JAMC-D-19-0135.1, 2020.
Siedersleben, S. K., Platis, A., Lundquist, J. K., Djath, B., Lampert, A., Bärfuss, K., Cañadillas, B., Schulz-Stellenfleth, J., Bange, J., Neumann, T., and Emeis, S.: Turbulent kinetic energy over large offshore wind farms observed and simulated by the mesoscale model WRF (3.8.1), Geosci. Model Dev., 13, 249268, https://doi.org/10.5194/gmd-13-249-2020, 2020.

Skamarock, W., Klemp, J., Dudhia, J., Gill, D., Barker, D., Wang, W., and Powers, J.: A Description of Advanced Research WRF, Tech. Rep. NCAR/TN-468+STR, NCAR, NCAR, Boulder, Colorado, USA, 2007.

Smedman, A.-S., Tjernström, M., and Högström, U.: Analysis of the turbulence structure of a marine low-level jet, Bound.-Lay. Meteorol., 66, 105-126, 1993.

Smedman, A.-S., Bergström, H., and Högström, U.: Spectra, variance and length scales in a marine stable boundary layer dominated by a low level jet, Boundary-Layer Meteorol, 76, 211-232, 1995.

Tay, K., Koh, T., and Skote, M.: Characterizing mesoscale variability in low-level jet simulations for CBLAST-LOW 2001 campaign, Meteorol. Atmos. Phys., 133, 163-179, https://doi.org/10.1007/s00703-020-00736-3, 2020.

Tennekes, H. and Lumley, J. L.: A first course in turbulence, The MIT Press, 1972.

Thompson, G., Rasmussen, R. M., and Manning, K.: Explicit forecasts of winter precipitation using an improved bulk microphysics scheme. Part-I: Description and sensitivity analysis, Mon. Weather Rev., 132, 519-542, 2004.

Tomaszewski, J. M. and Lundquist, J. K.: Simulated wind farm wake sensitivity to configuration choices in the Weather Research and Forecasting model version 3.8.1, Geosci. Model Dev., 13, 2645-2662, https://doi.org/10.5194/gmd-13-26452020, 2020.

Valenzuela, G.: Theories for the interaction of electromagnetic and ocean waves - A review, Bound.-Lay. Meteorol., 13, 61-85, 1978.

van der Walt, S., Colbert, S. C., and Varoquaux, G.: The NumPy Array: A Structure for Efficient Numerical Computation, Comput. Sci. Eng., 13, 22-30, https://doi.org/10.1109/MCSE.2011.37, 2011.

Volker, P. J., Hahmann, A. N., Badger, J., and Jørgensen, H. E.: Prospects for generating electricity by large onshore and offshore wind farms, Environ. Res. Lett., 12, 034022, https://doi.org/10.1088/1748-9326/aa5d86, 2017.

Volker, P. J. H., Badger, J., Hahmann, A. N., and Ott, S.: The Explicit Wake Parametrisation V1.0: a wind farm parametrisation in the mesoscale model WRF, Geosci. Model Dev., 8, 3715-3731, https://doi.org/10.5194/gmd-8-3715-2015, 2015.

Wagner, D., Steifeld, G., Witha, B., Wurps, H., and Reuder, J.: Low Level Jets over the Southern North Sea, Meteorol. Z., 28, 389415, 2019. 